Nat. Hazards Earth Syst. Sci., 19, 2183-2205, 2019

https://doi.org/10.5194/nhess-19-2183-2019

(C) Author(s) 2019. This work is distributed under

the Creative Commons Attribution 4.0 License.

\title{
Environmental controls on surf zone injuries on high-energy beaches
}

\author{
Bruno Castelle ${ }^{1,2}$, Tim Scott ${ }^{3}$, Rob Brander ${ }^{4}$, Jak McCarroll $^{3}$, Arthur Robinet ${ }^{5}$, Eric Tellier ${ }^{6,7,8}$, Elias de Korte ${ }^{9}$, \\ Bruno Simonnet $^{8}$, and Louis-Rachid Salmi ${ }^{6,7,10}$ \\ ${ }^{1}$ CNRS, UMR EPOC, Univ. Bordeaux, Pessac, France \\ ${ }^{2}$ UMR EPOC, Univ. Bordeaux, Pessac, France \\ ${ }^{3}$ Coastal Processes Research Group, School of Biological and Marine Sciences, University of Plymouth, Plymouth, UK \\ ${ }^{4}$ School of Biological, Earth and Environmental Sciences, UNSW Sydney, Sydney, Australia \\ ${ }^{5}$ Bureau de Recherche en Géologie Minière, Orléans, France \\ ${ }^{6}$ INSERM, ISPED, Centre INSERM U1219 Bordeaux Population Health Research, Univ. Bordeaux, Bordeaux, France \\ ${ }^{7}$ ISPED, Centre INSERM U1219 Bordeaux Population Health Research, Univ. Bordeaux, Bordeaux, France \\ ${ }^{8}$ Pôle Urgences Adultes, CHU de Bordeaux, SAMU-SMUR, Bordeaux, France \\ ${ }^{9}$ Institute for Marine and Atmospheric Research, Department of Physical Geography, Faculty of Geosciences, \\ Utrecht University, Utrecht, the Netherlands \\ ${ }^{10}$ Pôle de Santé Publique, CHU de Bordeaux, Service d’Information Médicale, Bordeaux, France
}

Correspondence: Bruno Castelle (bruno.castelle@u-bordeaux.fr)

Received: 28 March 2019 - Discussion started: 13 May 2019

Revised: 1 August 2019 - Accepted: 29 August 2019 - Published: 9 October 2019

\begin{abstract}
The two primary causes of surf zone injuries (SZIs) worldwide, including fatal drowning and severe spinal injuries, are rip currents (rips) and shore-break waves. SZIs also result from surfing and bodyboarding activity. In this paper we address the primary environmental controls on SZIs along the high-energy meso-macro-tidal surf beach coast of southwestern France. A total of 2523 SZIs recorded by lifeguards over 186 sample days during the summers of 2007, 2009 and 2015 were combined with measured and/or hindcast weather, wave, tide, and beach morphology data. All SZIs occurred disproportionately on warm sunny days with low wind, likely because of increased beachgoer numbers and hazard exposure. Relationships were strongest for shore-break- and rip-related SZIs and weakest for surfingrelated SZIs, the latter being also unaffected by tidal stage or range. Therefore, the analysis focused on bathers. More shore-break-related SZIs occur during shore-normal incident waves with average to below-average wave height (significant wave height, $H s=0.75-1.5 \mathrm{~m}$ ) and around higher water levels and large tide ranges when waves break on the steepest section of the beach. In contrast, more rip-related drownings occur near neap low tide, coinciding with maximised channel rip flow activity, under shore-normal incident waves with $H s>1.25 \mathrm{~m}$ and mean wave periods longer than $5 \mathrm{~s}$. Addi-
\end{abstract}

tional drowning incidents occurred at spring high tide, presumably due to small-scale swash rips. The composite wave and tide parameters proposed by Scott et al. (2014) are key controlling factors determining SZI occurrence, although the risk ranges are not necessarily transferable to all sites. Summer beach and surf zone morphology is interannually highly variable, which is critical to SZI patterns. The upper beach slope can vary from 0.06 to 0.18 between summers, resulting in low and high shore-break-related SZIs, respectively. Summers with coast-wide highly (weakly) developed rip channels also result in widespread (scarce) rip-related drowning incidents. With life risk defined in terms of the number of people exposed to life threatening hazards at a beach, the ability of morphodynamic models to simulate primary beach morphology characteristics a few weeks or months in advance is therefore of paramount importance for predicting the primary surf zone life risks along this coast.

\section{Introduction}

Sandy surf beaches are an attractive environment for a variety of recreational activities globally, including sunbathing, swimming and wading, bodyboarding, and surfing (West, 
2005). However, surf beaches can also be dangerous environments to those who choose to enter the water, due to potentially powerful wave conditions, strong currents, and the risk of collision and impact injury involving surf craft. Although global statistics are not available, annual fatal drownings on surf beaches worldwide are at least in the hundreds (Gilchrist and Branche, 2016).

It is well established that the leading cause of both fatal and non-fatal drowning incidents on surf beaches worldwide are strong, narrow, seaward-flowing rip currents (hereafter referred to as "rips"). Rips often originate close to the shoreline and can extend well beyond the breakers (Brander and Scott, 2016). They are capable of transporting bathers of all swimming abilities offshore into deeper water, increasing the risk of drowning through panic and exhaustion (Brander et al., 2011; Drozdzewski et al., 2012, 2015). Annually, they are responsible for an estimated 57 and 21 fatal drownings on surf beaches in the United States and Australia, respectively, alone (NOAA, 2017; Brighton et al., 2013). They are also considered to be the cause of the vast majority of lifeguard rescues and surf zone injuries (SZIs) in most documented regions of the world (e.g. $81 \%$ in the US, USLA, 2015; $57.4 \%$ in Australia, Brighton et al., 2013; $34 \%$ in the UK, RNLI, 2017). Although rips can form through a variety of driving mechanisms and have different hydrodynamic behaviours, they are essentially driven by the action of breaking waves (Castelle et al., 2016a). One of the most common rip types worldwide flows through channels incised in nearshore sandbars (e.g. MacMahan et al., 2006; Houser et al., 2013; Winter et al., 2014). These channel rips exhibit considerable natural variability in terms of flow characteristics and behaviour (McCarroll et al., 2018), preventing the public promotion of any single simple and universal escape strategy for those who find themselves caught in one (Bradstreet et al., 2014; McCarroll et al., 2014, 2015; Castelle et al., 2016b).

More recently, attention has been given towards the threat posed to bathers by shore-break waves associated with plunging and dumping waves at the shorelines of steep beaches. The concentrated and intense wave impact can cause SZIs, including severe spine injuries, to those caught in the impact zone (Robles, 2006; Puleo et al., 2016). Shorebreak waves are, on average, associated with a low proportion of surf zone rescues and injuries in most of existing studies (e.g. $8.5 \%$ of leading cause of rescue in Australia, Brighton et al., 2013; $13 \%$ in UK, RNLI, 2017), although higher proportions can be found $(44.6 \%$ of the SZIs on the coarser-grained and steeper beaches of southwestern France in Castelle et al., 2018a). More locally, shore-break waves were found to be responsible for over $82 \%$ of the SZIs on the steep beaches of Ocean City, Maryland (Muller, 2018). Another group of SZIs, which has received somewhat less attention and has been systematically treated separately from incidents involving bathers, are injuries associated with surfing, bodyboarding and other surf craft. Such high-risk activity (Diehm and Armatas, 2004) can lead to a wide spec- trum of sustained spinal pathologies (Dimmick et al., 2013; Nathanson, 2013), sprains and strains, fractures, dislocations, and lacerations (Moran and Weber, 2013) for the surf craft users and other people in the water. Lacerations, which are caused by the sharp fin, tail or nose of the surfboard, are the most common injuries sustained whilst surfing (Lowdon et al., 1983; Nathanson, 2013).

Several attempts have been made to correlate the occurrence of these surf zone hazards and, in some cases, resulting rescues and SZIs with environmental conditions. In the case of rips, it is well established that channel rip activity is controlled by offshore wave conditions (e.g. Brander, 1999; MacMahan et al., 2005; Castelle et al., 2006; Austin et al., 2010; Bruneau et al., 2011; Winter et al., 2014) and tide elevation (Aagaard et al., 1997; MacMahan et al., 2006; Bruneau et al., 2009; Austin et al., 2014). Surf zone morphology is also critical to rip activity, with deeper rip channels resulting in more intense rips (Brander, 1999; Aagaard and Vinther, 2008; Moulton et al., 2017a; McCarroll et al., 2018). Given that rip speed is an effective proxy for the physical hazard posed by rips (Moulton et al., 2017b) and that warm sunny days with low winds typically result in increased beach attendance and beachgoer exposure to hazards (Ibarra, 2011), rip risk predictors based on simple correlations between meteorological, oceanographic conditions and the incidence of rip-related rescues have been developed (Lushine, 1991; Lascody, 1998; Dusek and Seim, 2013).

Such simple risk predictors are challenged in high-energy meso-macro-tidal environments. Large water level variations deeply modulate rip flow and hazard (Austin et al., 2013) and breaker type (Wright and Short, 1984) and beachgoer exposure can be strongly reduced for large waves as high surf tends to discourage beachgoers from entering the surf zone. However, beachgoer exposure data are unavailable in most instances. Therefore, reported SZI incidents and/or rescues provide information on the full life risk signal (Stokes et al., 2017), where life risk can be defined in terms of the number of people exposed to life threatening hazards at a beach and their vulnerability to those hazards (Kennedy et al., 2013):

liferisk $=$ hazard $\times$ exposure.

In contrast to rips, studies on environmental controls on shore-break-related SZIs are scarce and show poor correlations. For example, along the Delaware coast of the United States, Puleo et al. (2016) did not find any statistically significant relation between shore-break-related SZIs and environmental factors such as tidal stage and foreshore slope. Although plunging and/or shore-break waves are known to occur for long-period waves and/or steep beach slopes (Battjes, 1974), Puleo et al. (2016) only noted that the highest injury rates were associated with moderate wave heights. They therefore suggested that shore-break-related SZI rates are primarily related to human factors. Finally, to our knowledge there is no scientific contribution to the environmental 
controls on SZIs sustained whilst using various types of surf craft.

Understanding the environmental controls on life risk along the coast requires accurate SZI records combined with detailed wave, tide and weather data at the time of the incidents. Focusing on rips along the meso-macro-tidal ripchannelled beaches of Devon and Cornwall in the southwestern UK, Scott et al. (2014) compared the average frequency distribution of key environmental parameters (e.g. wave height, tide elevation, wind speed) with those computed from the environmental parameters associated with each recorded rip incident. Differences between the distributions showed that high-risk, high-exposure scenarios for bathers occur disproportionately around mean low water on days with below average wave height, long wave period, shorenormal wave approach and light winds. Scott et al. (2014) further developed two composite wave and tide parameters for which thresholds were successful in discriminating between high life risk events. However, it is unclear if these composite parameters work for other beaches (globally) and if similar thresholds are found, and it is unknown if they can be useful for other SZIs such as those caused by shore-break waves or sustained whilst surfing.

Morphological beach state, which exerts a strong control on the hazard posed by rips (Wright and Short, 1984) and shore-break waves (Battjes, 1974), is constantly evolving on the timescales from days (storms) to seasonal to multi-annual scales (e.g. Splinter et al., 2014, 2018; Pianca et al., 2015; Davidson et al., 2017; Dodet et al., 2019), owing to changes in wave regimes. However, all existing SZI and rip-rescue studies have overlooked the influence on life risk at the beach from key morphological parameters, such as variations in rip channel depth or upper beach slope. The influence of interannual morphological changes on interannual life risk variability at a given coast is largely unexplored. Finally, shore-break and rip SZIs and/or rescues have been systematically treated separately in previous work, despite the fact that they can coexist at certain surf beaches (Castelle et al., 2018a).

The southwestern coast of France hosts $230 \mathrm{~km}$ of mesomacro-tidal sandy beaches that are visited by millions of tourists each summer (Brumaud, 2016) and are considered to be surf beaches. Castelle et al. (2018a) showed that along this stretch of coast, a large number of bather SZIs occur due to shore-break waves and channel rips, with a large number of additional SZIs sustained whilst surfing. The combination of large tide range and variable incident energetic wave climate and weather conditions result in complex and highly variable patterns of SZIs. The primary aim of this paper is to build upon the dataset of lifeguard-reported incidents of SZIs used by Castelle et al. (2018a) by examining extensive environmental data, including local to large-scale morphological data, to address the primary environmental controls on the full life risk spectrum at a high-energy meso-macrotidal coast. This study also aims to address the genericity of the two composite wave and tide parameters to discrimi- nate between low and high life risk conditions. This contribution is the first to study the environmental controls, including coastal morphology, on all primary causes and activity leading to SZIs and has strong implications towards future beach safety management and education of beach users in southwestern France and globally, particularly if the parameters can be generalised.

\section{Regional setting}

The study area is the Gironde and Landes coasts in southwestern France, which extends $230 \mathrm{~km}$ from the Adour estuary in the south to the Gironde estuary in the north (Fig. 1a). The coastline is interrupted only by the large-scale Arcachon inlet separating the Landes and Gironde coasts in the south and north, respectively (Fig. 1a). Beaches are relatively straight (Fig. 1b) and primarily composed of fine to medium quartz sand with a mean grain size varying from 200 to $400 \mu \mathrm{m}$, increasing southwards (Lorin and Viguier, 1987). They are all backed by high and wide coastal dunes (Tastet and Pontee, 1998), except along some of the coastal towns (Capbreton, Mimizan, Biscarrosse, Montalivet, Soulac and Lacanau; see Fig. 1; Castelle et al., 2018b). Beaches are exposed to high-energy ocean waves generated in the North Atlantic Ocean coming from the west-northwest direction (Butel et al., 2002; Castelle et al., 2017). Overall, the wave height very slightly increases $(<10 \%)$ southwards because of the narrowing continental shelf reducing the bottom friction, resulting in less energy dissipation of the incoming ocean waves (Castelle et al., 2018b). The coast is meso-macro-tidal with the tidal range marginally increasing northwards $(<15 \%)$ owing to the widening continental shelf (Le Cann, 1990). Neap tidal range is typically smaller than $1.5 \mathrm{~m}$, with the highest astronomical tidal range reaching approximately $5 \mathrm{~m}$. The beaches are rip-dominated (e.g. Bruneau et al., 2011) and mostly intermediate double barred (Castelle et al., 2007). The outer bar is modally crescentic (Lafon et al., 2005; Almar et al., 2010), while the inner bar is predominantly rip-channelled (Fig. 1b). Rip spacing of the inner and outer bars is about 400 and $700 \mathrm{~m}$, respectively, and progressively decreases northwards (Castelle et al., 2007).

The wave climate and resulting beach morphology are strongly seasonally modulated. Offshore of Truc Vert, which is located approximately at the centre of the study region, the monthly averaged significant wave height $(H s)$ peaks at $2.4 \mathrm{~m}$ during winter in January with a dominant $\mathrm{W}$ direction. The $99.5 \%$ significant wave height quantile $H s 99.5 \%$ is $5.6 \mathrm{~m}$ and severe storms $H s>8 \mathrm{~m}$ can occur in winter. In contrast, summers are characterised by milder waves with a monthly mean $H s$ of approximately $1.2 \mathrm{~m}$ and a dominant west-northwest direction (Castelle et al., 2017), although storms with $H s>$ $3 \mathrm{~m}$ can occur. In summer, beaches become more reflective with the inner bar often migrating from a transverse bar and rip state to a more reflective low-tide terrace state according 

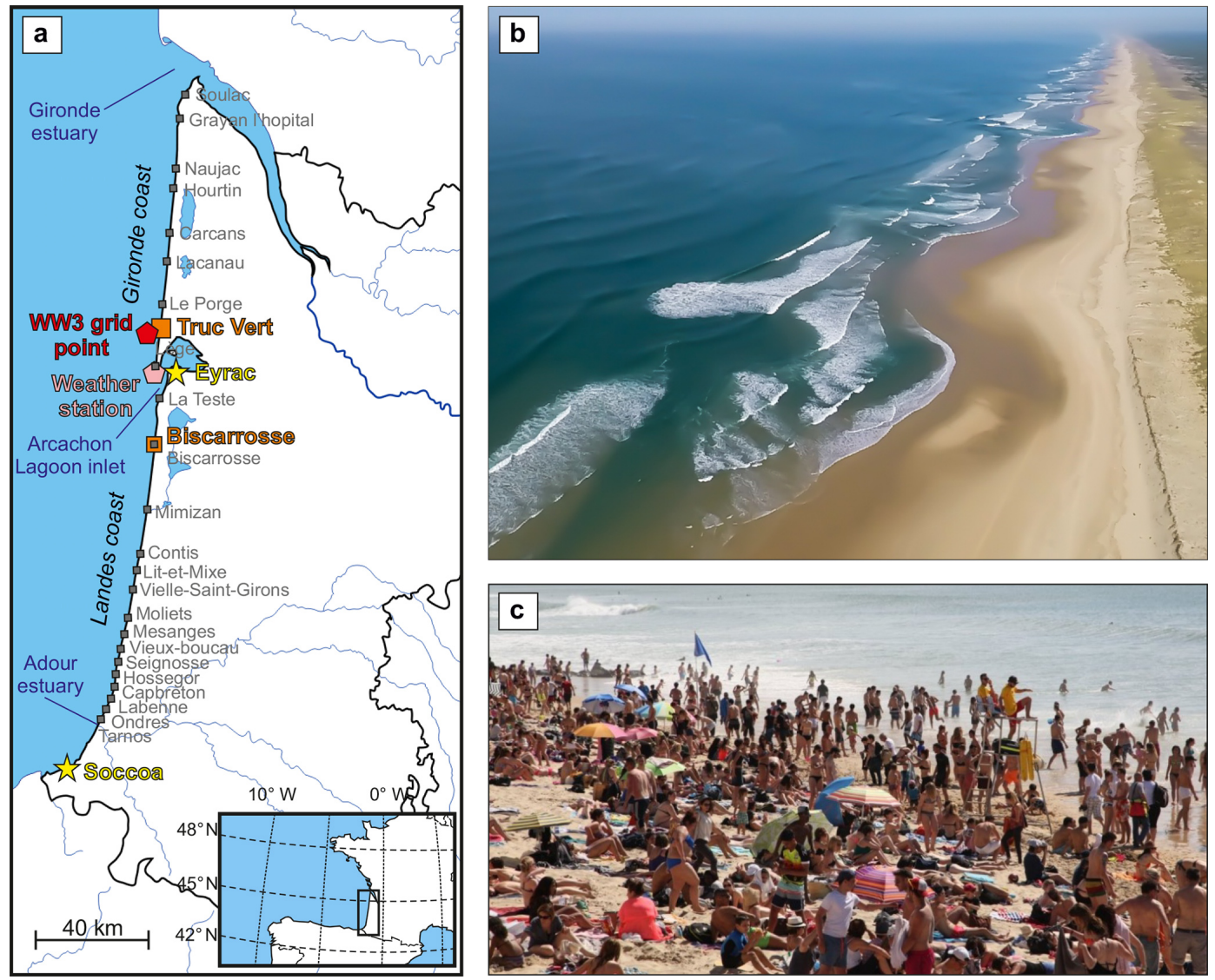

Figure 1. (a) Location map of southwestern France showing the $230 \mathrm{~km}$ long sandy beach study location encompassing the Gironde and Landes coasts between the Adour and Gironde estuaries. Grey squares indicate coastal municipalities where incident or injury report forms were gathered, yellow stars indicate tide gauges, and the red and pink polygons show the location of the Wave Watch III (WW3) model output grid point and weather station, respectively. (b) Aerial photograph of Truc Vert beach taken at low tide, showing a landscape representative of the southwestern French beaches with deep rip channels and steeper upper beach slopes (Ph. Vincent Marieu). (c) Crowded beach during summer at high tide with lifeguards supervising a bathing area delimited by two blue flags, typically extending no more than $100 \mathrm{~m}$ alongshore (Ph. Julien Lestage).

to the classification of Wright and Short (1984). Steeper upper beach slopes during summer also favour beach cusp development in the vicinity of the high-tide mark, and beaches are usually steeper in the south owing to larger mean grain size (Lorin and Viguier, 1987). Summer beach morphology is also strongly variable from year to year in relation to the strong interannual wave climate variability (Robinet et al., 2016; Dodet et al., 2019).

Beaches are characterised by strong rips primarily flowing through the inner-bar rip channels (Bruneau et al., 2011, Fig. 1b) with mean flow speeds reaching $1 \mathrm{~m} \mathrm{~s}^{-1}$ even in relatively low wave energy conditions $(<1 \mathrm{~m}$ wave height; Castelle et al., 2016b). Rip flow is tide-modulated (through modulation of breaking wave patterns) with maximum rip activity typically between low tide and mid-tide in summer wave conditions (Bruneau et al., 2009). In addition, near high tide, waves can break close to the shoreline on the steepest beach sections, creating hazardous shore-break conditions.
The southwestern coast of France also hosts some of the finest surfing beaches in Europe, attracting many surfers. During busy summer months, large numbers of surfers of all abilities, including surf schools, expose themselves to hazards related to surfing activity. Beaches are patrolled by lifeguards during the summer months of July and August, with extended periods of patrols at the busiest beaches, with a designated and supervised bathing zone. However, given the length of the coast and the many remote beach access paths through coastal dune tracks from inland car parks, many access points are situated on unpatrolled sections of beaches, kilometres away from any lifeguard presence. Approximately 4-5 million tourists, primarily from France and other European nations, come to the Gironde and Landes coasts each year to enjoy the beaches (Brumaud, 2016), simultaneously exposing themselves to surf zone hazards (Fig. 1c). Thousands of SZIs are sustained each year, of which over a thousand are documented by lifeguards in in- 
jury report forms (Castelle et al., 2018a). Overall, SZIs sustained range from mild contusion to fatal drowning and include severe spinal injuries, wounds and dislocation (Castelle et al., 2018a).

\section{Data}

The dataset of lifeguard-reported incidents of SZIs in southwestern France presented in Castelle et al. (2018a) is combined with extensive environmental data to address the primary environmental controls and high-risk conditions leading to bather SZIs caused by shore-break waves and channel rips and to SZIs sustained whilst surfing. The environmental dataset includes weather data, local beach and large-scale coastal morphology, and tide and wave hindcasts.

\subsection{SZI data}

The SZI dataset collected in Castelle et al. (2018a) is used here for further analysis. Each time a medical incident occurs on the beach, a lifeguard responds to the scene to provide patient care and to potentially assist paramedics. An injury report form, as detailed in Castelle et al. (2018a), is filed for every incident. A total of 2523 SZIs over 186 sample days during the summers of 2007, 2009 and 2015 were collected and examined by Castelle et al. (2018a), who addressed the epidemiology of SZIs. Amongst all the data analysed in Castelle et al. (2018a), only date and time $(<10 \mathrm{~min}$ accuracy) of the incident, beach location, categorically ticked activity (e.g. wading, surfing, bodyboarding), cause of injury (e.g. rip current, shore-break waves), and injury type (e.g. drowning, spine injury) are used herein. In addition, opentext-field comments in the form were sometimes used, for instance, to understand the cause of incident (e.g. collision against someone else, or against their own surfboard) as there is no such box to tick in the forms provided. In the case of a drowning incident, the drowning stage was also provided according to a four-stage classification widely used in France (Menezes and Costa, 1972; Dupoux et al., 1981): (1) exhaustion but no sign of aspiration of water; (2) moderate respiratory impairment, anxiety; (3) altered consciousness, severe respiratory impairment or acute pulmonary oedema, tachycardia or hypotension; and (4) coma, respiratory or cardiac arrest.

Overall, Castelle et al. (2018a) showed that while rips cause the most severe injuries (drowning), a large number of SZIs, including severe spinal injuries, are caused by shorebreak waves. Another large proportion of injuries are related to surfing and bodyboarding activity. Within the beachgoer cohort, surfers do not enter the water for the same reasons as regular bathers. Therefore, in the present contribution we discriminate between injuries (1) sustained while surfing or bodyboarding, whatever the cause, hereafter referred to as surfing-related injuries $33.5 \%$ of the dataset, $n=844)$; (2) caused by rips but excluding surfers and bodyboarders $(8.7 \%$ of the dataset, $n=220)$, hereafter referred to as rip-related injuries, which essentially consist of fatal and non-fatal drowning incidents, with rips causing $83 \%$ of the drowning incidents reported; and (3) caused by shorebreak waves but excluding surfers and bodyboarders (41.7\% of the dataset, $n=1053$ ), which primarily result in contusion, sprain, or dislocation $(51 \% ; n=537)$ and spine injuries $(29.8 \%, n=314)$. For each SZI, the date, time and location (coastal municipalities in Fig. 1a) reported in the form were used to estimate the wave, tide and meteorological conditions at the time of the incident using the environmental dataset described below.

\subsection{Environmental data}

In order to obtain a continuous time series of wave conditions, 6-hourly outputs from a wave hindcast (Boudière et al., 2013) based on the spectral wave model Wave Watch III (Tolman, 2014) were used. The hindcast was performed on an unstructured grid with a resolution increasing from $10 \mathrm{~km}$ offshore to $200 \mathrm{~m}$ near the coast and has been extensively validated (Boudière et al., 2013; Ardhuin et al., 2012). Given the weak gradient in wave conditions along the coast, the wave data at grid point $44.7374^{\circ} \mathrm{N}, 1.3232^{\circ} \mathrm{W}$ at approximately $30 \mathrm{~m}$ in depth was used and considered representative of the entire coast (Castelle et al., 2018b). Using this dataset, each incident was associated with a significant wave height $\mathrm{Hs}$, mean and peak wave periods $T 02$ and $T p$, respectively, and wave angle $\theta$.

A tidal component analysis of a 3-month time series of continuous, storm-free, Soccoa tide gauge data (Fig. 1) was performed to reconstruct a tide level time series (elevation every $10 \mathrm{~min}$ ). The average phase lag between the Soccoa tide gauge and beaches of all coastal municipalities (grey squares in Fig. 1) was estimated using tide charts from the Service Hydrographique et Océanographique de la Marine (France). Errors due to the (time-varying) phase lag and amplitude difference between real and predicted tide result in an estimated maximum error in tide elevation of $0.3 \mathrm{~m}$ at all sites. Using this dataset, each incident was associated with a tide elevation $\eta$ and a daily tide range (TR).

We used RADOME (Réseau d'Acquisition de Données d'Observations Météorologiques Etendu), which is an automatic weather station network of Météo-France that collects meteorological data at 554 stations across France. Hourly data of air temperature $(T)$, mean wind speed $(W)$ and insolation $(I)$ collected at the Cap Ferret station (Fig. 1) were used to estimate weather conditions at the time of each incident. Given the relative homogeneity of the coast and weather patterns in the region, as well as the lack of other weather stations directly implemented on the coast, these data were assumed to be representative of the weather along the entire study area. The corresponding daily mean values $(\bar{T}, \bar{W}$ and 
$\bar{I})$, averaged during the patrolled hours between 11 and $19 \mathrm{~h}$, were also computed.

The morphological state of the beaches was estimated primarily using the topographic data collected at Truc Vert beach, located in the south of the Gironde coast (Fig. 1). From 8 April 2005 to present, topographic surveys have been performed at spring low tide every 2 or 4 weeks with an alongshore coverage that progressively increased from approximately $300 \mathrm{~m}$ in 2005 to approximately $1500 \mathrm{~m}$ since 2012 (Castelle et al., 2017). SPOT and Sentinel satellite large-scale images taken at low tide, which therefore show the intertidal inner-bar system, were collected. This morphological dataset was used to address the overall differences in beach morphology, rip channel characteristics and upper beach slope between the three summers.

Additional morphological data from Biscarrosse beach were also used. A field experiment was performed at Biscarrosse on 13-17 June 2007, during which the topo-bathymetry was accurately surveyed along approximately $2000 \mathrm{~m}$ of beach (Bruneau et al., 2009, 2011). This morphology, which can be assumed to be representative of the beach morphology throughout the 2007 summer, was used to address wave transformation and wave-driven currents during that summer. For this purpose, an Xbeach model (Roelvink et al., 2009) was implemented on a $10 \mathrm{~m} \times 10 \mathrm{~m}$ regular grid to address the influence of offshore wave conditions and tidal elevation on rip flow dynamics and resulting hazard. The model, which is depth-averaged and wave-group resolving, has been demonstrated to be suitable for this purpose even when default settings were used (Castelle et al., 2016b).

\section{Results}

\subsection{Environmental controls}

Figure 2 shows time series of environmental factors and SZIs, discriminating rip-related drownings and SZIs related to shore-break waves and surfing activity during the 2007 summer. This time series, which is representative in the patterns of the two other summers, clearly shows some complex relations between the occurrence of different SZIs and environmental factors. During this summer, the coast was exposed to a broad range of wave conditions, with $H s$ and $T p$ ranging between approximately 0.4 and $4 \mathrm{~m}$ and 5 and $16 \mathrm{~s}$, respectively, with waves coming from the southwest to the north but predominantly from the west-northwest (Fig. 2ac), resulting in highly variable amount of daily SZIs (Fig. 2j). The least temporally variable SZIs are those sustained whilst surfing, which occur almost throughout the summer (daily mean for the entire dataset $\bar{n}=4.5$, standard deviation $\sigma=$ 3.3). The only notable exception is for days with large daily mean wind speed $\bar{W}\left(>10 \mathrm{~m} \mathrm{~s}^{-1}\right)$, coming systematically from the southwest-northwest quadrant (not shown). These windy conditions systematically result in no, or a small num- ber, of surfing-related SZIs $(\bar{n}=1.0$ with a maximum of 4 , standard deviation $\sigma=1.5$ ). This is likely due to strong onshore winds being typically associated with messy and choppy sea states that strongly deteriorate surfing wave quality and, in turn, the number of surfers entering the water. Riprelated $(\bar{n}=1.2, \sigma=2.1)$ and shore-break-related $(\bar{n}=6.0$, $\sigma=8.0$ ) injuries are much more variable in time with many days with no injury reported. These injuries tend to occur in clusters with particular days prone to rip-related drowning incidents or shore-break-related SZIs (Fig. 2h, i). Clearly, days with a large number of drowning incidents caused by rips are not necessarily associated with a large number of shorebreak-related injuries and vice versa.

Considering the entire 3-year dataset, the number of rip- and shore-break-related daily injuries are weakly positively correlated $(r=0.28)$, similar to rip drowning incidents and surfing-activity-related injuries $(r=0.25)$, while shorebreak-related injuries are more correlated with injuries resulting from surfing activity $(r=0.43)$. A possible explanation of this larger correlation is that amongst all the reported surfing-related injuries $(n=844), 8.5 \%(n=72)$ were reported to be caused by shore-break waves, as opposed to $0.6 \%(n=5)$ caused by rips. This is in line with earlier studies showing that injuries resulting from surfing and bodyboarding occur more frequently in shore-break conditions (e.g. Beratan and Osborne, 1987; Chang et al., 2006).

Overall, there appears to be no single environmental factor controlling the occurrence of SZIs. Instead, it is possible that certain combinations of environmental controls are conducive to causing SZIs and that these combinations depend on the type of SZI. To better understand these combinations promoting life risk surf zone conditions, the approach of Scott et al. (2014) was utilised, whereby the environmental conditions during which incidents occurred were compared with the "average" background conditions of the 2007, 2009 and 2015 summer seasons. The environmental parameters addressed here are significant wave height, $H s$; mean wave period, $T 02$; peak wave period, $T p$; wave direction, $\theta$; tide or water level, $\eta$; daily tide range, TR; daily averaged air temperature, $\bar{T}$; insolation, $\bar{I}$; and wind speed, $\bar{W}$. The average frequency distribution of these parameters was compared with those computed from the environmental parameters associated with each recorded rip incident. Differences between the distributions therefore provides an indication of environmental conditions that may be driving SZIs (Scott et al., 2014).

Figure 3 provides insights into the environmental controls on surfing-related injuries in southwestern France. The frequency distributions $(F n)$ of the wave parameters related to reported incidents show some differences from the average background distributions with conditions of $H s=0.75-$ $1.5 \mathrm{~m}, T 02=6-8 \mathrm{~s}$ and $\theta=290-300^{\circ}$ being slightly overrepresented by $10.5 \%, 9.2 \%$ and $6.2 \%$, with $60.3 \%, 36.4 \%$ and $46.8 \%$ occurring within this range, respectively (Fig. 3ac). In contrast, water level does not substantially affect 

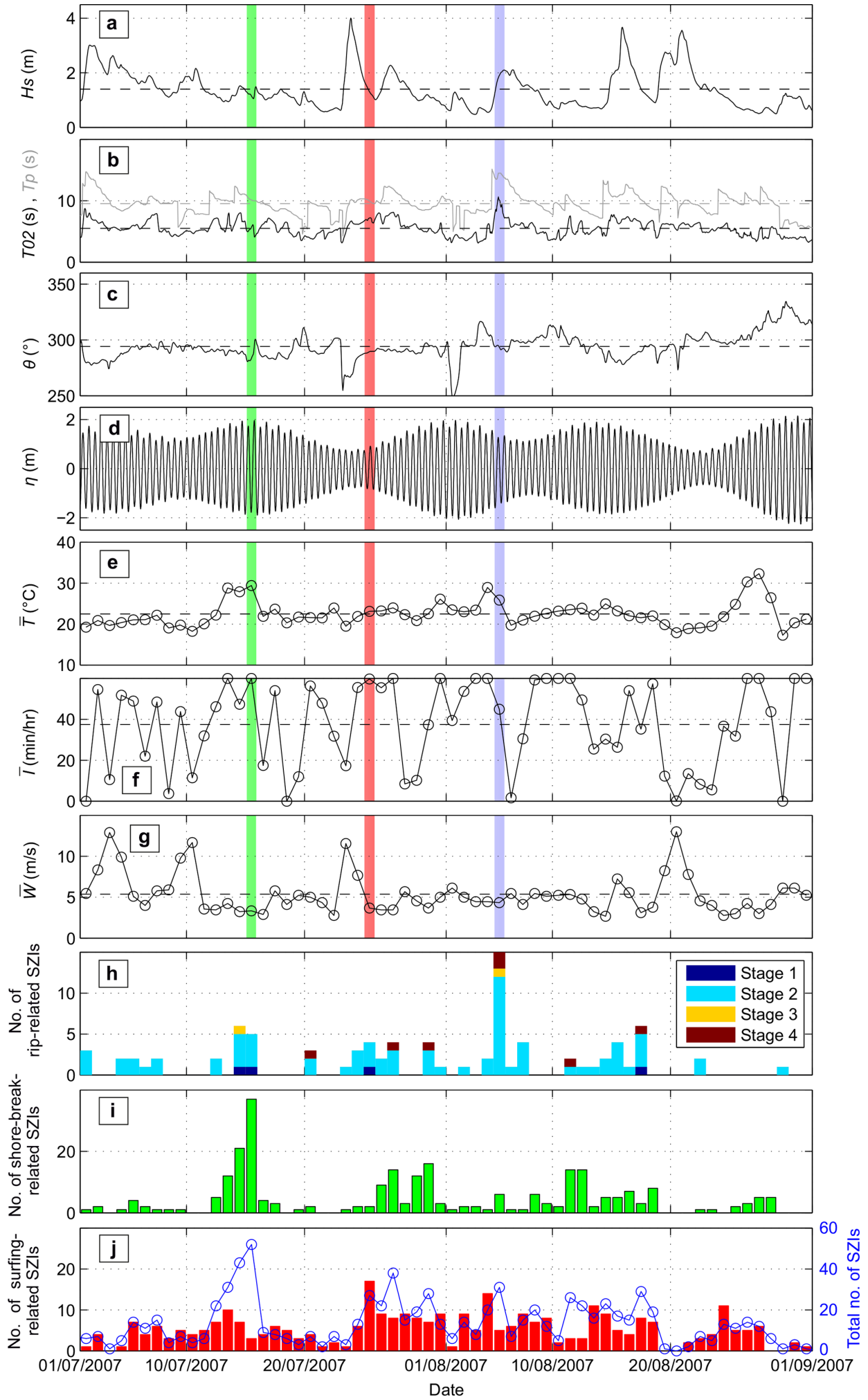

Figure 2. Time series during the 2007 summer of (a) significant wave height, $H s$; (b) peak and mean wave periods, $T p$ and $T 02$, respectively; (c) wave direction, $\theta$; (d) water level, $\eta$, with respect to mean sea level; (e) daily mean air temperature, $\bar{T}$; (f) daily mean hourly insolation, $\bar{I}$; (g) daily mean wind speed, $\bar{W}$; (h) distribution of rip-related SZIs; (i) distribution of shore-break-related SZIs; and (j) distribution of surfing-activity-related SZIs and total number of SZIs. In panels (a)-(g) the shaded green, red and blue vertical areas indicate the days with the largest number of shore-break-, surfing- and rip-related SZIs during the 2007 summer. In panels (a), (b), (c), (e), (f) the summer mean is indicated by the horizontal dashed line. 

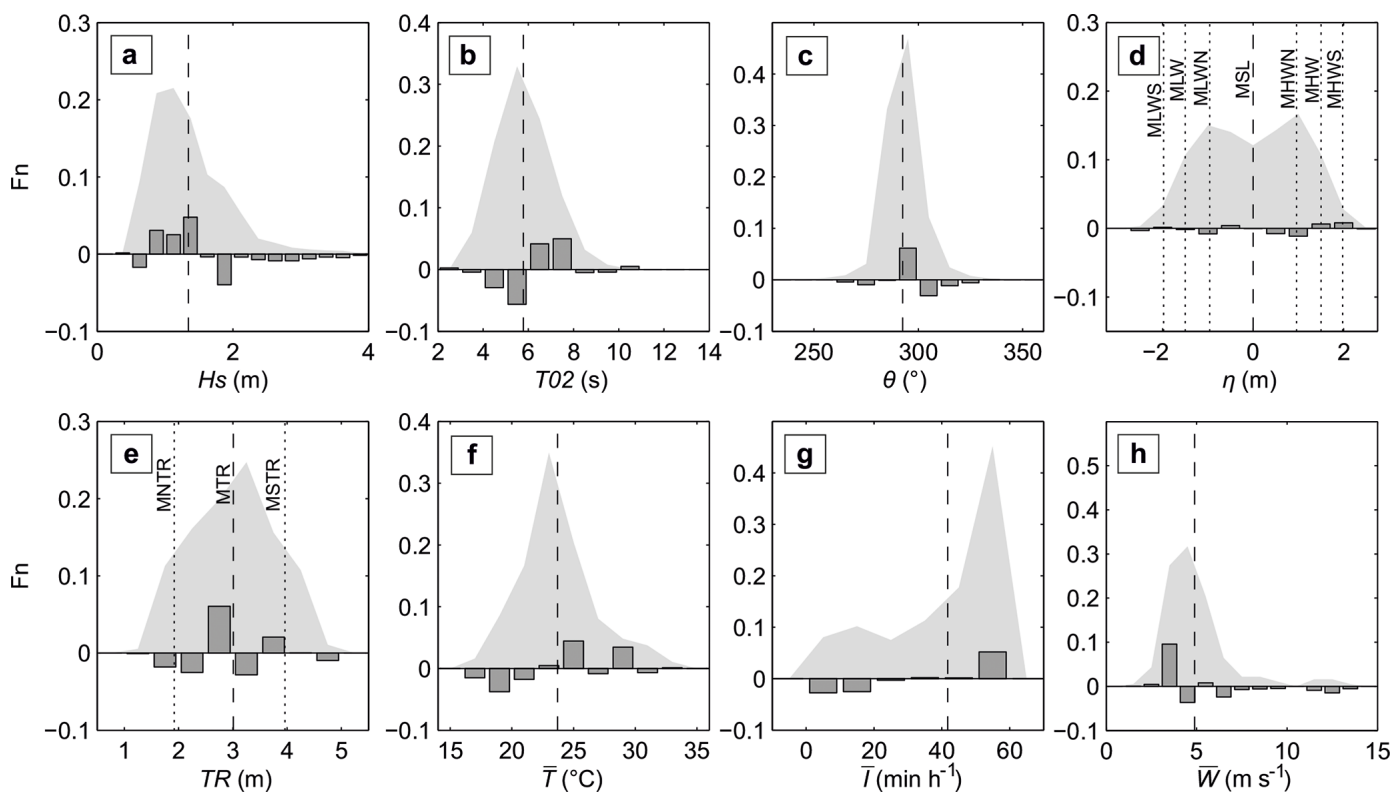

Figure 3. Environmental controls on surfing-activity-related SZIs: normalised frequency distributions Fn during the summers of 2007, 2009 and 2015 (light grey region), referred to as "average" background distribution, of (a) significant wave height, Hs; (b) mean wave period, $T 02 ;$ (c) wave direction, $\theta$; (d) water level, $\eta$; (e) daily tide range, TR; (f) daily mean air temperature, $\bar{T}$; (g) daily mean hourly insolation, $\bar{I}$; and (h) daily mean wind speed, $\bar{W}$. The dark grey bars show the difference between surfing-related and average background distributions and the vertical dashed lines indicate background means.

surfing-related incidents as no clear pattern stands out (Fig. 3d), while daily tidal range (TR) shows a local peak near the mid-tide range (MTR, Fig. 3e). Incidents occurring for low wind speed $\left(\bar{W}<4 \mathrm{~m} \mathrm{~s}^{-1}\right)$ and for warm and sunny weather $\left(\bar{T}>24^{\circ}, \bar{I}>50 \mathrm{minh}^{-1}\right)$ were overrepresented by 10.1, 6.6 and $5.2 \%$, with $32.2 \%, 38.2 \%$ and $45.2 \%$ occurring within this range, respectively (Fig. $3 \mathrm{f}-\mathrm{h}$ ). Therefore, more high-risk surfing incident scenarios occur on days with low to moderate (average to below average) wave height, large (above average) wave period $(T 02>6 \mathrm{~s}$ and $T p>9 \mathrm{~s}$, not shown), west-northwest incidence and warm sunny weather with low wind (below average), regardless of water level or daily tide range. As surfers can be considered a more experienced beachgoer community, the SZIs involving only bathers are assessed below, with shore-break- and rip-related injuries investigated separately.

Figure 4 shows the same analysis but for shore-breakrelated injuries and reveals more prominent and sometimes different patterns compared to surfing-related injuries. The most salient difference is that tide plays a critical role, with water level $\eta>1.25 \mathrm{~m}$ ( $>$ MHWN, mean high water neap) and daily tide range $\mathrm{TR}>3.5 \mathrm{~m}$ (spring tides) being over-represented by $32.5 \%$ and $10.6 \%$, with $13.5 \%$ and $27.4 \%$ occurring within this range, respectively (Fig. 4d, e). The influence of wave and weather conditions is also more pronounced than for surfing-related injuries. The frequency distributions of the wave parameters related to reported incidents show some large differences from the aver- age background distributions with conditions of $H s=0.75$ $1.5 \mathrm{~m}$ (average to below-average), $T 02>7 \mathrm{~s}$ (above-average) and $\theta=290-300^{\circ}$ being over-represented by $18.1 \%, 6.8 \%$ and $8.6 \%$, with $70.0 \%, 16.0 \%$ and $46.8 \%$ occurring within this range, respectively (Fig. $4 \mathrm{a}-\mathrm{c}$ ). Incidents occurring at low below-average wind speed $\left(\bar{W}<4 \mathrm{~m} \mathrm{~s}^{-1}\right)$ and for warm and sunny weather $\left(\bar{T}>24^{\circ}, \bar{I}>40 \mathrm{~min} \mathrm{~h}^{-1}\right)$ were overrepresented by $16.0 \%, 26.5 \%$ and $14.6 \%$, with $32.2 \%, 38.1 \%$ and $62.9 \%$ occurring within this range, respectively (Fig. 3fh). These are again in higher proportion than for surfingrelated injuries.

Figure 5 shows the same analysis for rip-related injuries. Similar to shore-break- and surfing-related injuries, more riprelated injuries occur on warm, sunny days with light wind. Days with low wind speed $\left(\bar{W}<4 \mathrm{~m} \mathrm{~s}^{-1}\right)$ and warm, sunny weather $\left(\bar{T}>24^{\circ}, \bar{I}>40 \mathrm{minh}^{-1}\right)$ were over-represented by $7.2 \%, 7.9 \%$ and $11.6 \%$, with $32.2 \%, 38.1 \%$ and $62.9 \%$ occurring within this range, respectively (Fig. $5 \mathrm{f}-\mathrm{h}$ ). While this over-representation is less important than for shorebreak-related injuries, it is slightly more pronounced than for surfing-related injuries. The control of waves on rip-related SZIs contrasts with that on the other SZIs. Larger waves with more shore-normal incidence increase the likelihood of riprelated injuries, as significant differences from the average background distributions are found for conditions of $H s>$ $1.25 \mathrm{~m}$ (average to above-average) and $\theta=280-290^{\circ}$, with over-representation by $22.1 \%$ and $13.6 \%$, with $47.7 \%$ and $33.2 \%$ occurring within this range, respectively (Fig. 5a, c). 

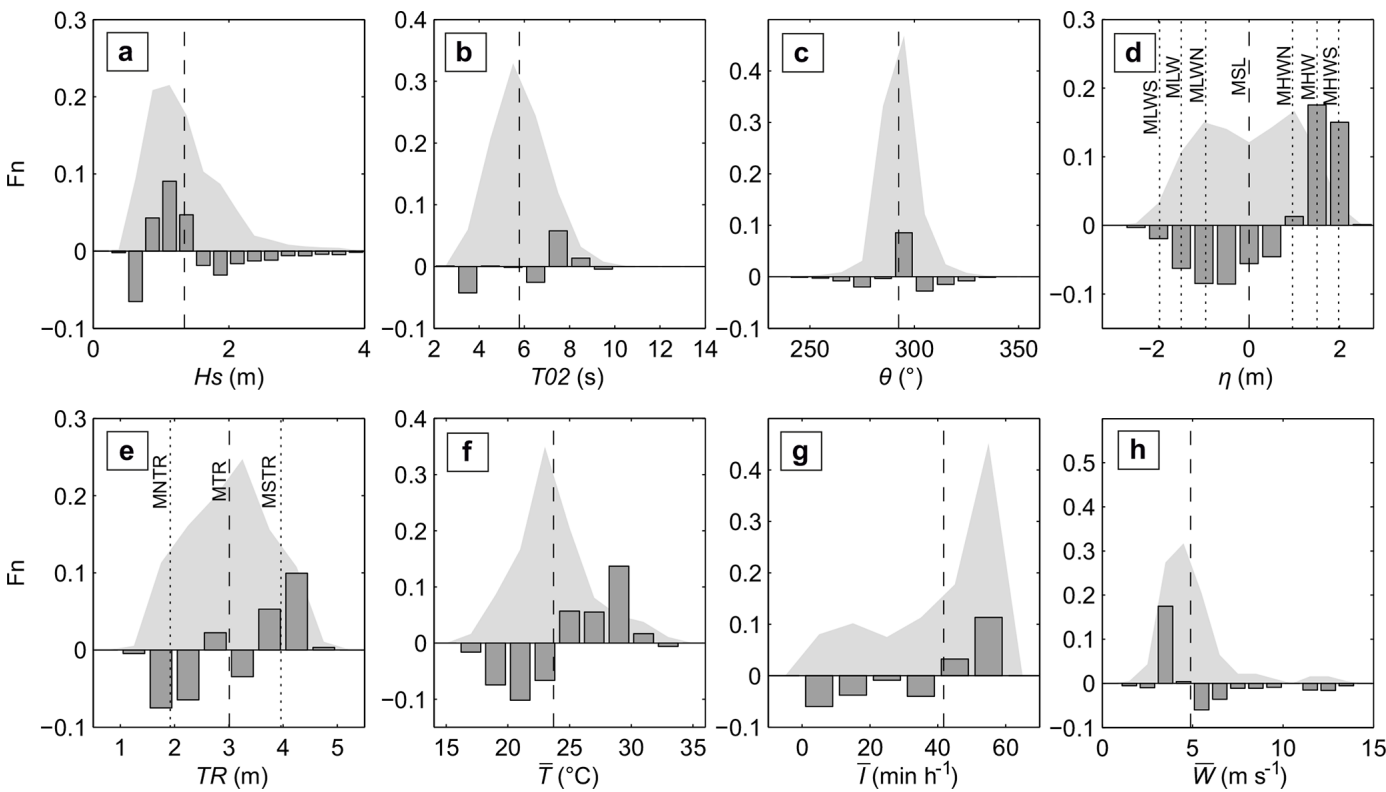

Figure 4. Environmental controls on shore-break-related SZIs: normalised frequency distributions, Fn, during the summers of 2007, 2009 and 2015 (light grey region), referred to as "average" background distribution, of (a) significant wave height, Hs; (b) mean wave period, $T 02 ;$ (c) wave direction, $\theta$; (d) water level, $\eta$; (e) daily tide range, TR; (f) daily mean air temperature, $\bar{T}$; (g) daily mean hourly insolation, $\bar{I}$; and (h) daily mean wind speed, $\bar{W}$. The dark grey bars show the difference between surfing-related and average background distributions and vertical dashed lines show the background mean.
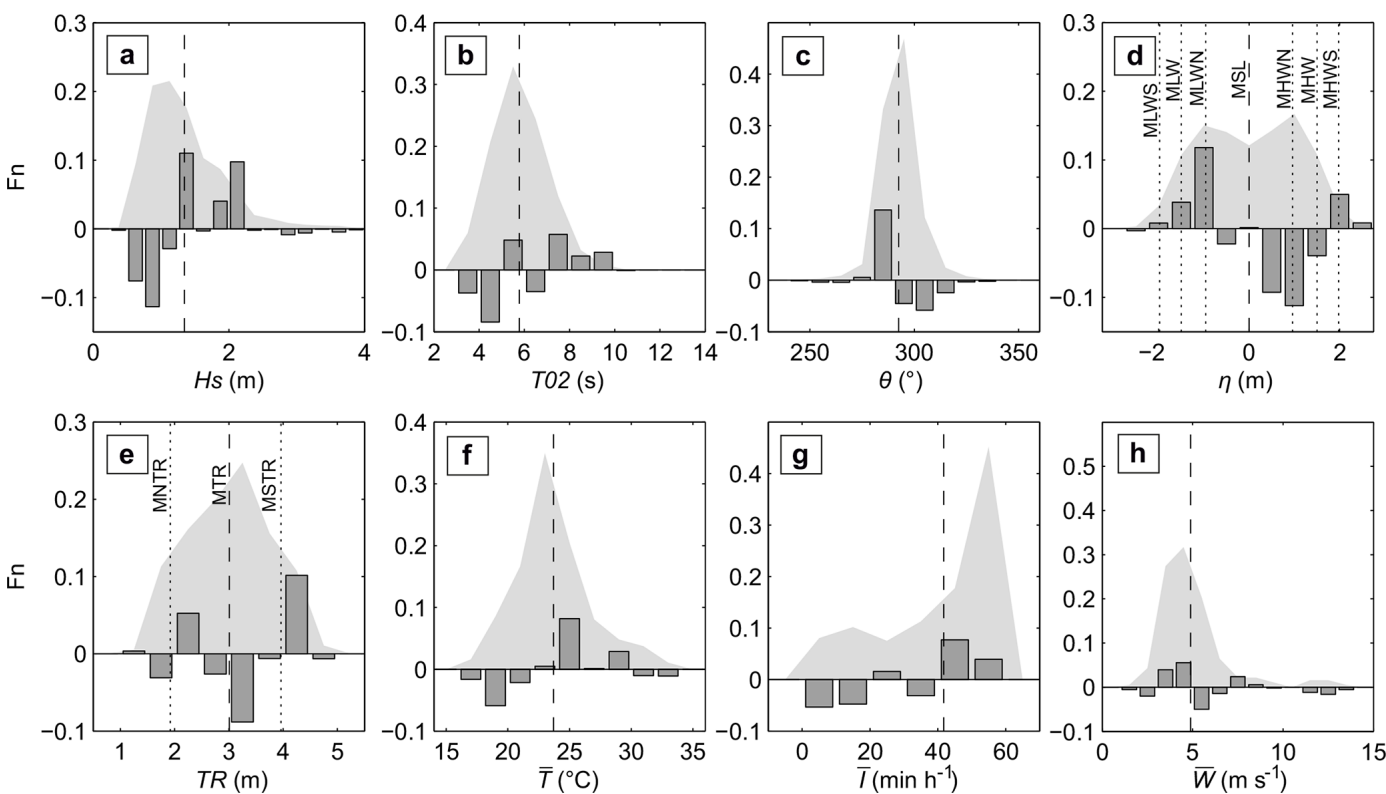

Figure 5. Environmental controls on rip-related SZIs: normalised frequency distributions, $F n$, during the summers of 2007,2009 and 2015 (light grey region), referred to as "average" background distribution, of (a) significant wave height, $H s$; (b) mean wave period, T02; (c) wave direction, $\theta$; (d) water level, $\eta$; (e) daily tide range, TR; (f) daily mean air temperature, $\bar{T}$; (g) daily mean hourly insolation, $\bar{I}$; and (h) daily mean wind speed, $\bar{W}$, with the dark grey bars in all panels showing the difference between the surfing-related and the average background distributions and the vertical dashed line showing the background mean. 
Even more contrasting is the role of tide that shows complex patterns. Low tide levels $\eta<-0.75 \mathrm{~m}$ and, to a lesser extent, extremely high tide levels $\eta>1.75 \mathrm{~m}$ are over-represented by $16.1 \%$ and $5.8 \%$, with $29.3 \%$ and $2.7 \%$ occurring within this range, respectively (Fig. 5d). The daily tide range does not show any clear pattern (Fig. 5e). This complex control of tide on rip-related injuries is discussed in Sect. 5.

\subsection{High life risk rip and shore-break days}

As shown in Fig. 2, during the 2007 summer the number of SZIs per day was highly variable, particularly rip- and shorebreak-related injuries, with some days having no incident reported and others with a large number of SZIs $(\bar{n}=13.6, \sigma=$ 11.9). Of the highest risk days, 15 July 2007 had the highest number of SZIs (60) with incidents reported across 17 coastal municipalities, which is the most widespread day in the entire time series (daily average number of municipalities reporting incidents $\bar{m}=7.4$, standard deviation $\sigma_{\mathrm{m}}=4.2$ ). During that day $68.3 \%(n=43)$ and $13.3 \%(n=8)$ were caused by shore-break waves and rips, respectively. The second day with the largest number of SZIs (59 across 16 coastal municipalities), 4 August 2009, was unusual because of very high shore-break life risk $81.4 \%(n=48)$ SZIs caused by shore-break waves. This corresponds to the day with the largest number of shore-break-related injuries in the entire dataset $(\bar{n}=6.0)$. Shore-break-related SZIs were widespread along the coast as reported across 14 coastal municipalities $\left(\bar{m}=3.9, \sigma_{\mathrm{m}}=3.6\right)$. Of note, no rip-related injury occurred on 4 August 2009. In contrast, 5 August 2007 was characterised by less reported SZIs $(n=37)$ but by very high rip life risk. On this day, $40.5 \%(n=15)$ of the reported incidents were drownings (maximum of the entire time series, $\bar{n}=1.2, \sigma=2.1)$ across eight different coastal municipalities $\left(\bar{m}=1.0, \sigma_{\mathrm{m}}=1.5\right)$, including one stage three and two deadly stage four incidents. Only $18.9 \%(n=7)$ of the SZIs on 5 August 2007 were caused by shore-break waves. While tide and wave conditions were very different for these two high-risk days, both days were characterised by warm, sunny weather with light wind, resulting in crowded beaches and high beachgoer exposure to surf zone hazards (Fig. 6). The wave and tide controls during these $2 \mathrm{~d}$ are now addressed in detail.

Figure 7 shows time series of SZIs, wave and tide conditions from $2 \mathrm{~d}$ prior to 5 August 2007 when the largest number of rip-related drownings in the entire dataset were reported. On 3-4 August 2007, the coast was exposed to lowenergy waves $(H s \approx 0.5 \mathrm{~m}, T p \approx 10 \mathrm{~s})$ with sunny weather $\left(\bar{I}=60 \mathrm{minh}^{-1}\right)$. The daily number of reported SZIs of 8 and 13 on 3 and 4 August 2007, respectively, was relatively low or average compared to the mean $(\bar{n}=13.6)$, with two stage two drowning incidents on 4 August. Given that the wave climate was similar for the $2 \mathrm{~d}$, it is hypothesised that the increased air temperature on 4 August $\left(\bar{T}=28.9^{\circ}\right)$ compared to 3 August $\left(\bar{T}=23.4^{\circ}\right)$ contributed to greater
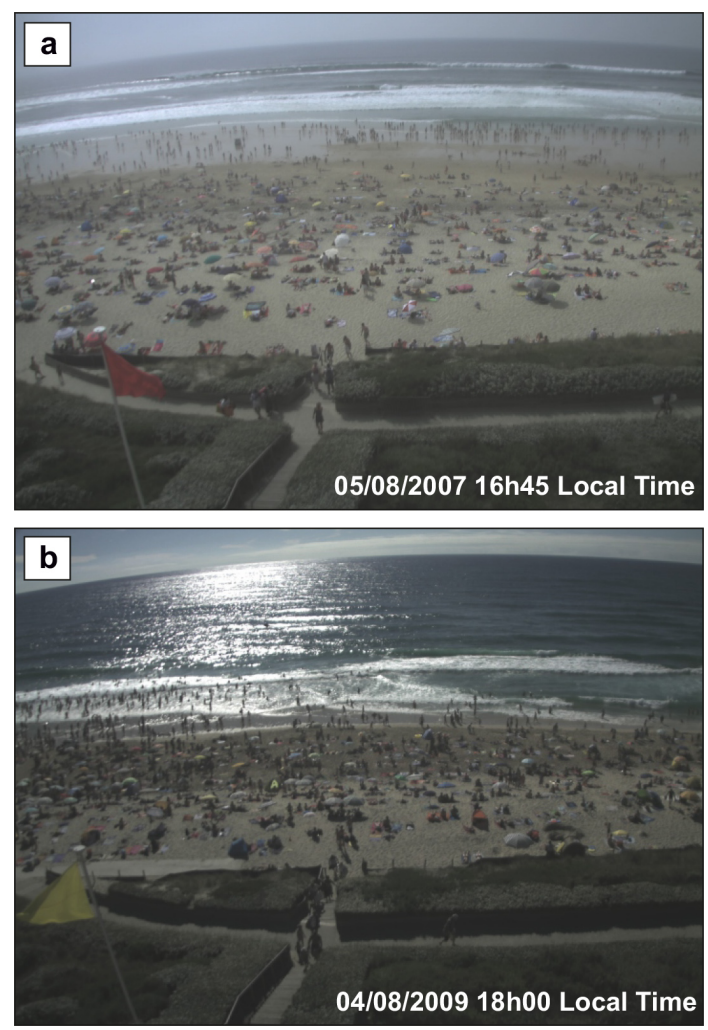

Figure 6. Snapshots of Biscarrosse beach from a video station (Angnuureng et al., 2017) during the days with the largest number of SZIs related to (a) rips on 5 August 2007 and (b) shore-break waves on 4 August 2009, with pictures taken approximately at the time of the most hazardous conditions (Figs. 7; 10). Note that in panel (a) the red flag is hoisted meaning that bathing was forbidden all along the beach due to the presence of rips.

beach attendance and beachgoer exposure to surf zone hazards and therefore a larger number of SZIs and higher life risk. It was still reasonably warm $\left(\bar{T}=25.9^{\circ}\right)$ and sunny $\left(\bar{I}=44.9 \mathrm{~min} \mathrm{~h}^{-1}\right)$ on 5 August 2007 and there was also high beach attendance (Fig. 6a). In contrast, on 4-5 August 2007 (the two previous days) the coast was exposed to a shorenormal high-energy groundswell $(H s \approx 2 \mathrm{~m}, T p \approx 14 \mathrm{~s})$ with low tide levels occurring later in the afternoon. The temporal distribution of rip-related drowning incidents is clearly modulated by tidal stage, as incidents were most numerous between low tide and mid-tide, decreased at low tide, and did not occur from mid-tide to high tide (Fig. 7a). Importantly, the number of drownings caused by rips on 5 August 2007 could have been much larger, as the red flag prohibiting bathing all along the beach was hoisted on many of the beaches in the afternoon (Fig. 6a), due to the large number of rescues and mass rescue interventions. This can also explain why rip-related SZIs on 5 August 2007 were reported across eight coastal municipalities. Rip-related SZIs were the most widespread on 25 July 2009 with 10 reporting coastal municipalities, under warm and sunny weather, shore-normal mod- 

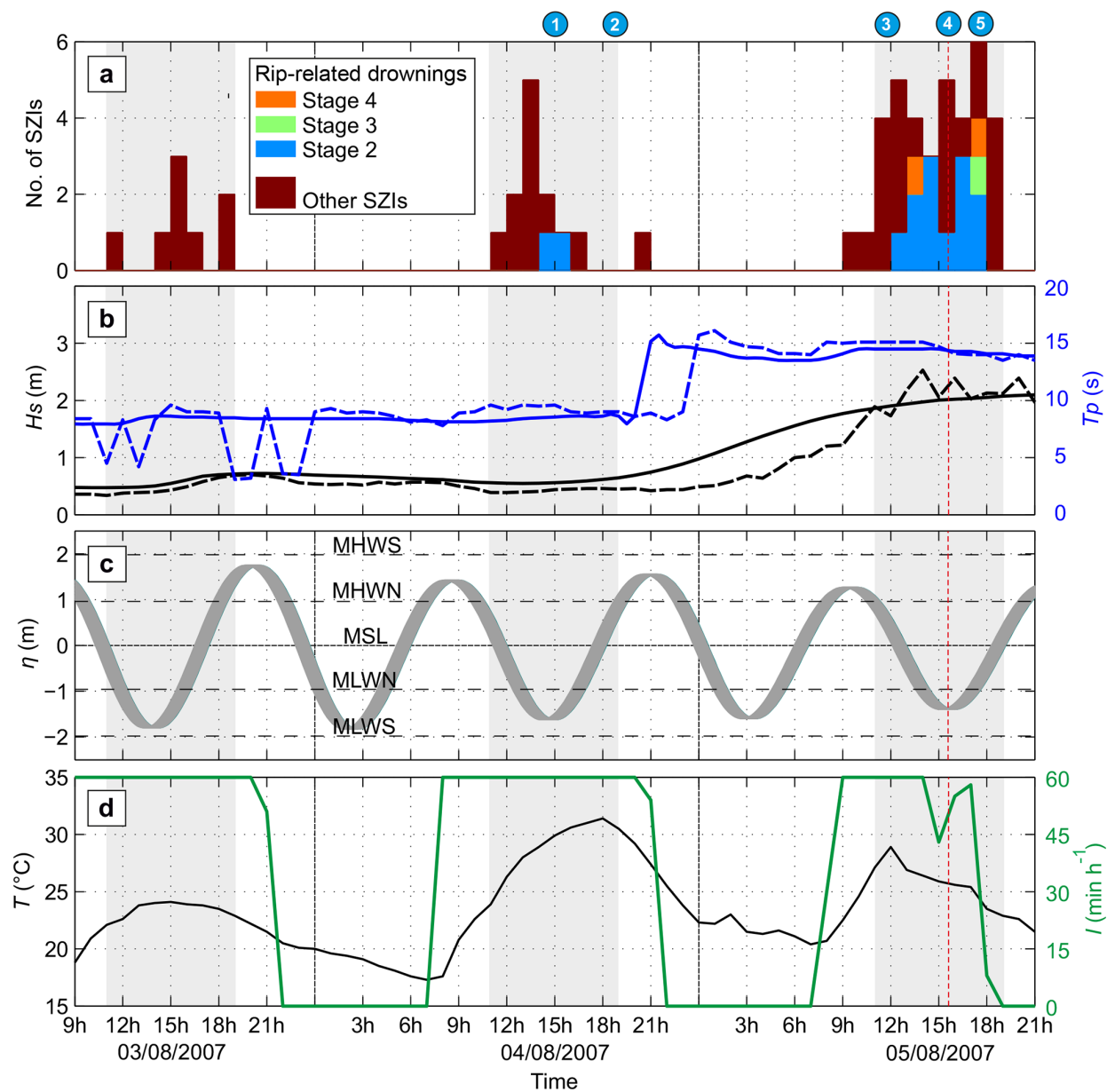

Figure 7. Time series on 3-5 August 2007, with 5 August having the largest number of rip-related drownings in the entire dataset, showing (a) distribution of SZIs, with indicators of rip-related drowning and drowning stage coloured; (b) significant wave height, $H s$, and peak wave period, $T p$, from the model (solid) and from the Candhis directional wave buoy in $50 \mathrm{~m}$ depth facing Truc Vert, which worked only intermittently during the three summer seasons; (c) tide elevation, $\eta$; (d) hourly air temperature, $T$, and insolation, $I$. In all panels, the light grey areas show the lifeguard-patrolled hours. In all panels the vertical dashed red line indicates low-tide occurrence on 5 August 2007 . The blue circles on top of panel (a) indicate the timing of the wave-driven current simulations shown in Fig. 8b-f.

erate energy waves $(H s \approx 1.4 \mathrm{~m}, T p \approx 9 \mathrm{~s})$, and spring low tide occurring in mid-afternoon. However, on 25 July 2009 only 12 non-fatal drowning incidents (four stage one and eight stage two) were reported, corresponding to smaller rip life risk than on 5 August 2007 (no stage one, 12 stage two, 1 stage three and 2 fatal drownings).

To further explore the influence of wave and tide conditions on rip activity on 4-5 August 2007, Fig. 8 shows modelled breaker and wave-driven current patterns (using the morphology surveyed in mid-June 2007 at Biscarrosse in Bruneau et al., 2009) at relevant times indicated by the blue circles in Fig. 7. At low tide (15 h) on 4 August 2007, when two moderate (stage two) drowning incidents were reported (Fig. 9a), low- to moderate-energy rips $\left(0.3-0.4 \mathrm{~m} \mathrm{~s}^{-1}\right.$ mean offshore velocities) were predicted by the model to flow through a reasonably narrow surf zone (Event 1 ), corresponding to a moderate rip hazard. In contrast, $4 \mathrm{~h}$ later between mid-tide and high tide, there was no rip activity observed along the entire beach and in turn no rip hazard posed to bathers, which is consistent with the absence of reported rip-related SZIs (Event 2). On 5 August 2007 simulations show that rips were active throughout the entire tide cycle for energetic shore-normal incident groundswell conditions. Breaker and wave-driven current patterns at 12, 15 and $17 \mathrm{~h}$ are shown in Fig. 8d-f (Events 3-5). The time slot with the largest number of reported rip-related drownings (two stage two, one stage three, two stage four) occurred between 17 and $18 \mathrm{~h}$ (Event 5, Fig. 8f), that is, between low tide and mid-tide $(\eta \approx-0.9 \mathrm{~m})$. Simulations show the presence of wide (over $200 \mathrm{~m}$ ) breakers with high-energy rips (0.8-1.2 $\mathrm{m} \mathrm{s}^{-1}$ mean velocities) flushing the surf zone. These rips are associated with intense alongshore northerly and southerly feeder currents, locally reaching $1.5 \mathrm{~m} \mathrm{~s}^{-1}$ and running close to the shoreline (Fig. 8f). These flow patterns 

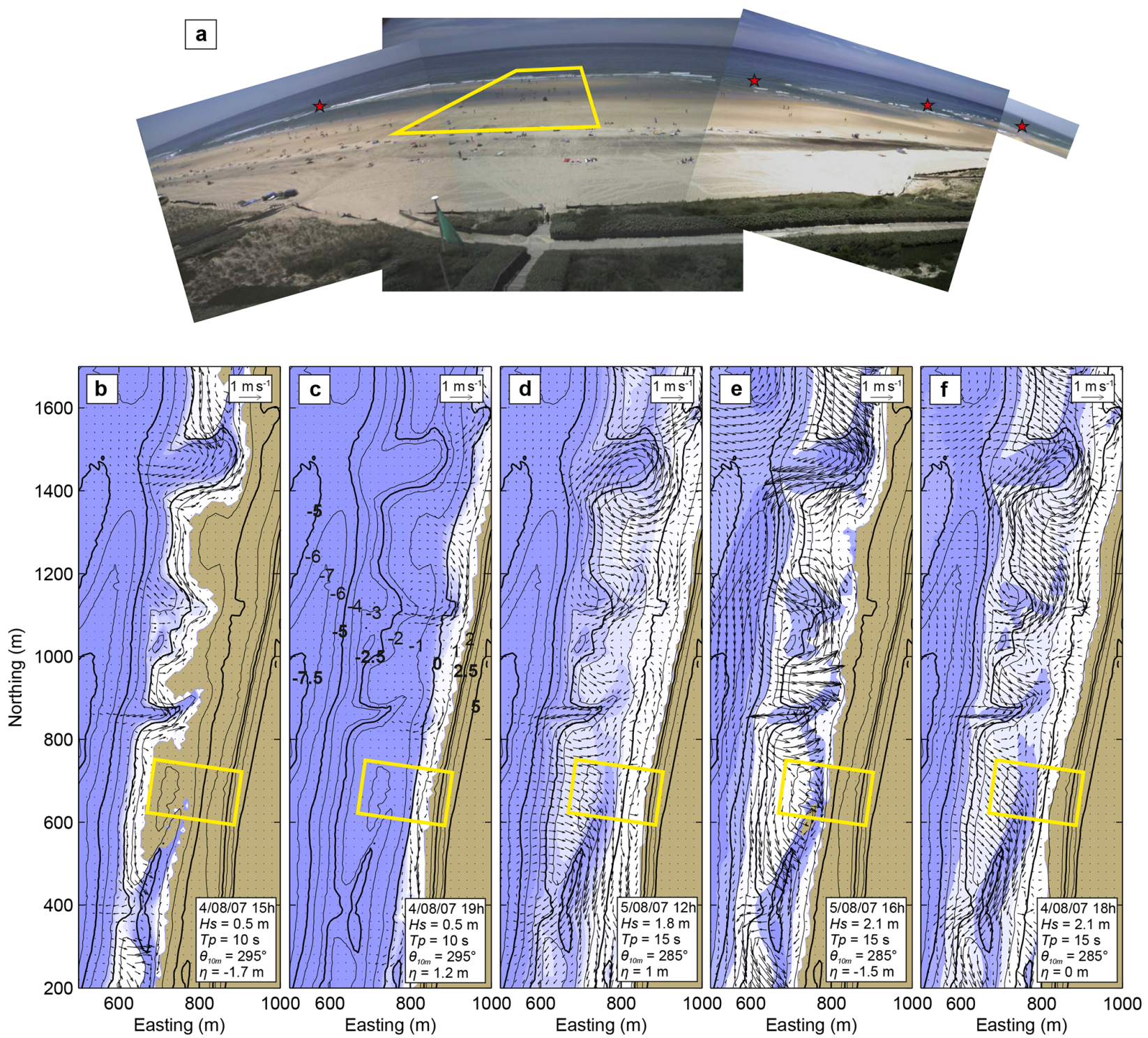

Figure 8. (a) Biscarrosse beach on 18 June 2007 with red stars showing rip channel locations. The bottom panels show wave-driven currents (arrows) and breaking wave patterns (white areas) simulated at the same beach during the five times on 5 August 2007 indicated by the blue circles in Fig. 9a for the following wave and tide conditions: (b) $6 \mathrm{Hs}=0.5 \mathrm{~m}, T p=10 \mathrm{~s}, \theta_{10 \mathrm{~m}}=295^{\circ}, \eta=-1.7 \mathrm{~m}$; (c) $H s=0.5 \mathrm{~m}$, $T p=10 \mathrm{~s}, \theta_{10 \mathrm{~m}}=295^{\circ}, \eta=1.2 \mathrm{~m}$; (d) $H s=1.8 \mathrm{~m}, T p=15 \mathrm{~s}, \theta_{10 \mathrm{~m}}=285^{\circ}, \eta=1 \mathrm{~m}$; (e) $H s=2.1 \mathrm{~m}, T p=15 \mathrm{~s}, \theta_{10 \mathrm{~m}}=285^{\circ}, \eta=-1.5 \mathrm{~m}$; (f) $H s=2.1 \mathrm{~m}, T p=15 \mathrm{~s}, \theta_{10 \mathrm{~m}}=285^{\circ}, \eta=0 \mathrm{~m}$. In panels (b)-(f), the yellow box shows the preferred location of the swim-between-theflags area at Biscarrosse beach during most of the 2007 summer, and the topo-bathymetry is contoured in the background with contour elevation indicated in panel (c) with respect to mean sea level.

therefore have a high potential to rapidly transport unsuspecting bathers wading close to the shoreline into strong seawardflowing rips, which could take them $300 \mathrm{~m}$ offshore in less than 5 min. Similar patterns are simulated earlier in the day for similar water levels but slightly milder wave conditions (Event 3, Fig. 8d). Rips were the most intense (1-1.5 $\mathrm{m} \mathrm{s}^{-1}$ mean velocities) at low tide ( $\eta=-1.5 \mathrm{~m}$, Event 4 , Fig. $8 \mathrm{e}$ ). However, feeder currents were, overall, less intense and/or ran further offshore, which may explain why fewer drown- ing incidents were reported the same day for higher water levels (Fig. 8d, f).

Our results indicate that the most hazardous rip conditions were caused by a high-energy shore-normal groundswell ( $H s \approx 2 \mathrm{~m}, T p \approx 14 \mathrm{~s}$ ), with low tide levels maximising hazard in the afternoon, with risk also maximised due to high beachgoer afternoon exposure owing to warm and sunny weather. Such wave conditions are, however, quite rare in summer along the southwestern coast of France. The largescale atmospheric patterns that resulted in these anomalous 


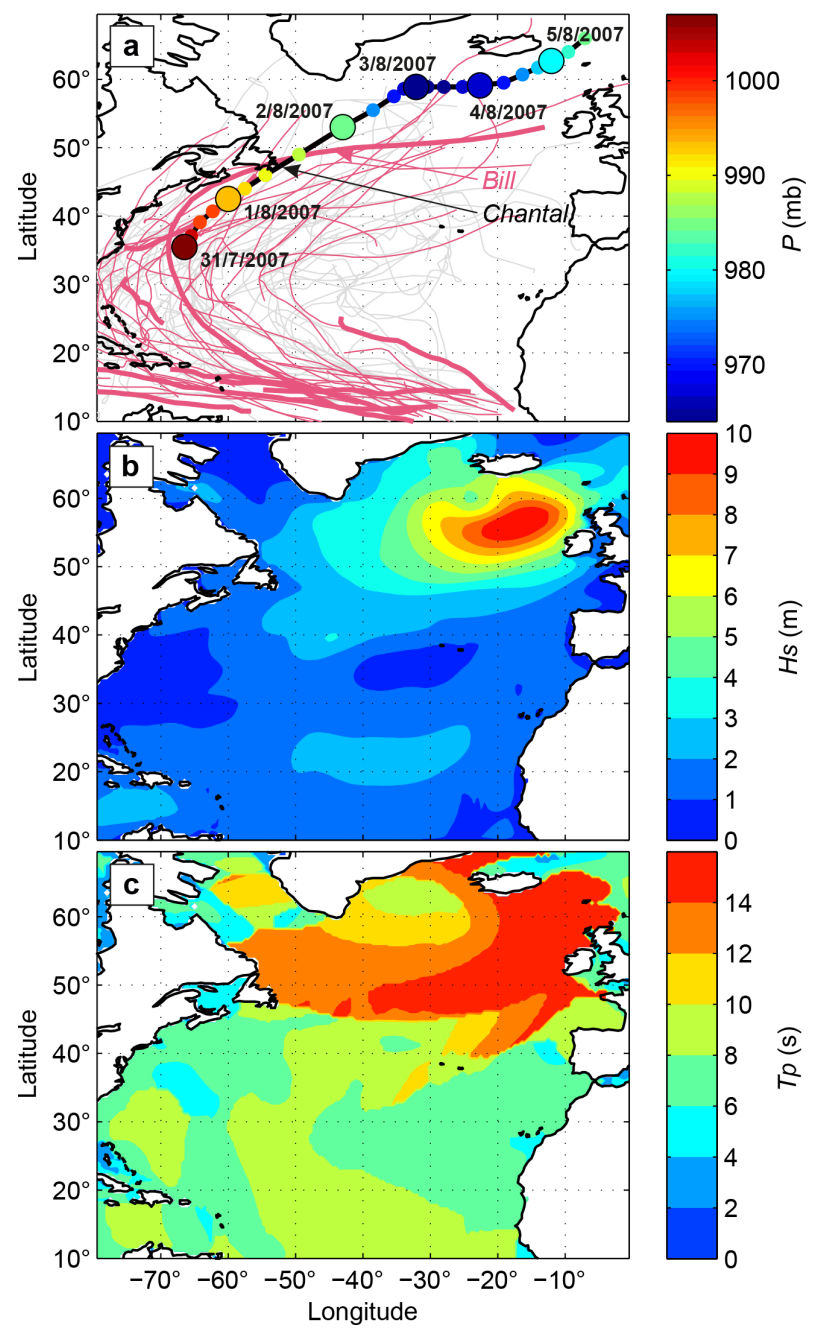

Figure 9. Atmospheric conditions and resulting wave fields causing the most hazardous rip conditions of the dataset along the southwestern French beaches on 5 August 2007: (a) trajectory, daily position (large circles), and minimum central pressure of tropical cyclone Chantal, superimposed onto all tropical cyclone trajectories over the period 2007-2017 (light grey) and limited to the JulyAugust summer periods (dark prink) and only summers 2007, 2009 and 2015 (thick dark pink). (b) Significant wave height $H s$ and (c) peak wave period field on 4 August 02:00 LT.

wave conditions are analysed in Fig. 9. Over a period of $5 \mathrm{~d}$ prior to 5 August 2007 a tropical depression intensified into Tropical Storm Chantal on 31 July, while located at approximately $35^{\circ} \mathrm{N}$ in the western Atlantic. The storm tracked northeastward through an area of progressively colder water and cooler air and transitioned into an extratropical cyclone on 1 August. It subsequently intensified to attain winds of near hurricane force, and on 3 August the cyclone underwent a slowly weakening trend in the far North Atlantic Ocean. This storm track drove high-energy waves, funnelling towards the Atlantic coast of Europe with $H s$ peaking at al- most $10 \mathrm{~m}$ offshore of Ireland (Fig. 9b), coming from the $W$ and with $T p$ exceeding $14 \mathrm{~s}$ (Fig. 9c).

The occurrence of high-energy groundswell events such as those on 5 August 2007 is clearly linked with storm activity and trajectory during the hurricane season. The hurricane season officially begins on 1 June and ends on 30 November each year, with tropical storm and cyclone activity peaking in September. August and July are characterised by weaker tropical storm and cyclone activity. However, as shown by the trajectories of all tropical cyclones between 2005 and 2017 (light grey) and the July-August periods (dark pink) in Fig. 9a, there were quite a large number (12) of tropical cyclones that tracked northeastward across the North Atlantic at $>40^{\circ} \mathrm{N}$ in July-August. These weather patterns have the potential to generate high-energy waves towards the beaches of southwestern France like those observed on 5 August 2007. It is worth noting that only two tropical cyclones tracking northeastward at $>40^{\circ} \mathrm{N}$ were observed during the summers of 2007, 2009 and 2015, including Tropical Storm Chantal. The other one was the long-lasting (1526 August 2009) Hurricane Bill which drove above-average wave height $(0.8 \mathrm{~m}<H s<2 \mathrm{~m})$ and period $(9 \mathrm{~s}<T p<15 \mathrm{~s})$ near-shore-normal incident waves in southwestern France between 20 and 28 August 2009. Although coinciding with below-average air temperature and partly cloudy weather at the end of the summer touristic season, likely resulting in decreased beachgoer numbers and hazard exposure, the period was characterised by 15 drowning incidents including 2 fatal incidents.

Figure 10 shows the time series of SZIs, wave and tide conditions spanning the $2 \mathrm{~d}$ prior to 4 August 2009 when the largest number of shore-break-related SZIs in the entire dataset were reported. During the $3 \mathrm{~d}$, incident wave conditions varied slightly with $0.7<H s<1.5 \mathrm{~m}, 7.5<T p<10$ s and $280^{\circ}<\theta<300^{\circ}$ with higher tide level occurring midafternoon, and high tide occurring increasingly late in the day. The major difference between the $3 \mathrm{~d}$ is the warmer and sunnier weather on 4 August 2009. This likely resulted in high beach attendance and beachgoer exposure which, coinciding with higher tide levels, resulted in a large number of shore-break-related injuries. Given that wave conditions were similar to modal summer wave conditions in southwestern France, it suggests that maximised shore-break-related risk occurs for moderate energy wave conditions, hot and sunny days, and high tides that occur in late afternoon, when beach attendance is maximised. This is further emphasised in Fig. 11, which shows that days with milder temperature $\left(\bar{T}<22^{\circ}\right)$ or smaller $(H s<0.6 \mathrm{~m})$ or larger $(H s>$ $2 \mathrm{~m}$ ) waves systematically result in a reduced occurrence of shore-break-related SZIs. For intermediate wave conditions $(0.6 \mathrm{~m}<H s<2 \mathrm{~m})$, the number of shore-break-related SZIs increases with increasing daily maximum tidal elevation between 15 and $19 \mathrm{~h} \eta_{\max }$ when beach attendance is maximised during warm and sunny days. For such intermediate wave 

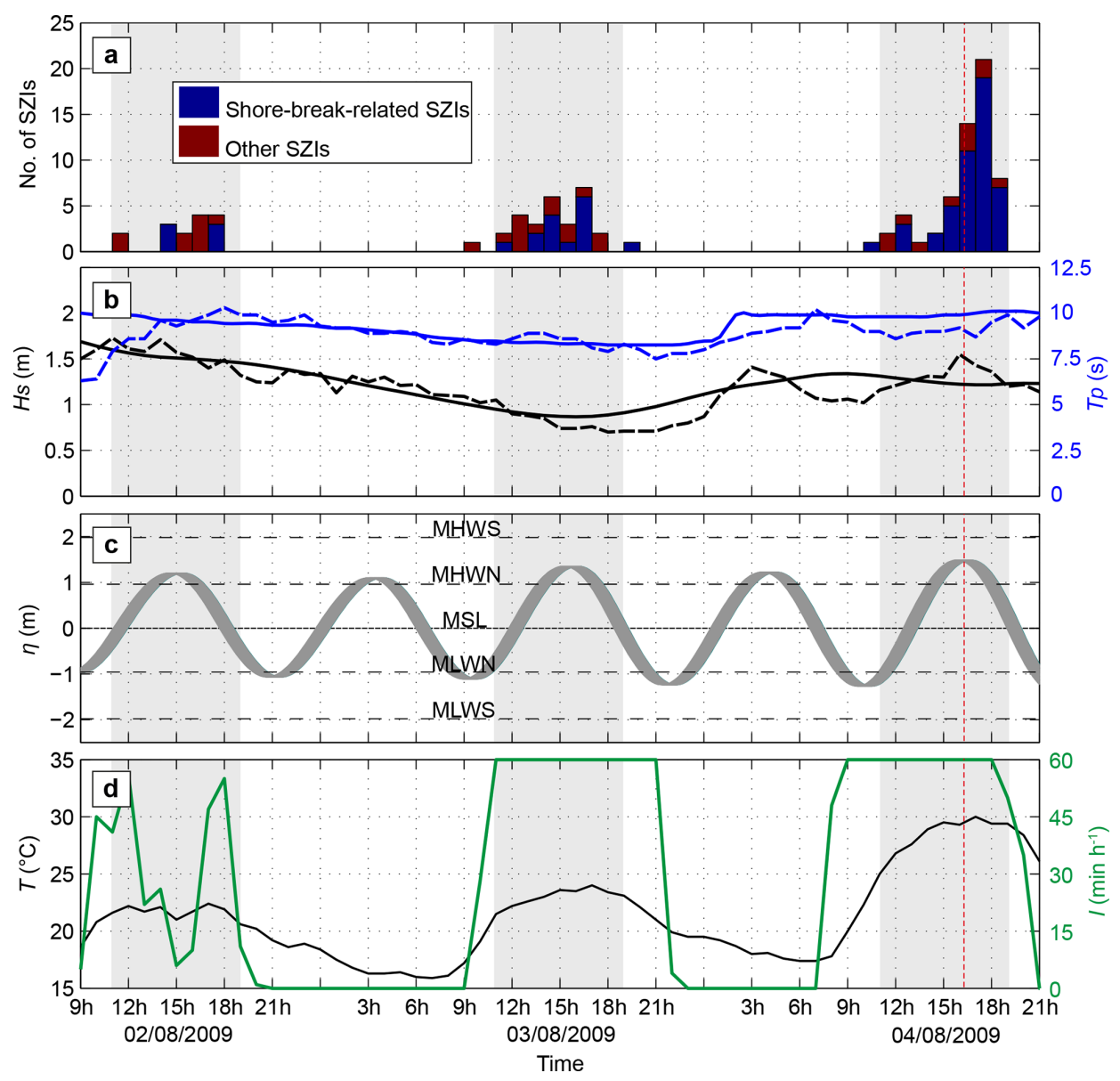

Figure 10. Time series on 2-4 August 2009, with 4 August having the largest number of shore-break-related injuries in the entire dataset, showing (a) distribution SZIs with indication of shore-break-related injuries; (b) significant wave height, $H s$, and peak wave period, $T p$, from the model (solid) and from the Candhis directional wave buoy in $50 \mathrm{~m}$ depth facing Truc Vert, which only worked intermittently during the three summer seasons; (c) tide elevation, $\eta$; (d) hourly air temperature, $T$, and insolation, $I$. In all panels, the light grey areas show lifeguard-patrolled hours. In all panels the vertical dashed red line indicates low-tide occurrence on 4 August 2009.

conditions, high-risk shore-break conditions are clearly observed for $\eta_{\max }>1.25 \mathrm{~m}$ and $\bar{T}>22^{\circ}$ (Fig. 11).

\section{Discussion}

Both shore-break- and rip-related SZIs involving bathers were found to occur disproportionately on warm sunny days with low winds. Although no beachgoer exposure data were available in this study, such environmental conditions are commonly found to contribute to increased beach attendance and beachgoer exposure to hazards (e.g. Ibarra, 2011; Balouin et al., 2014). It is possible to estimate beach attendance using video monitoring systems (e.g. Guillen et al., 2008); however, it was not possible to apply such an approach in this study. The Biscarrosse video station (Angnuureng et al., 2017), which is the only suitable video station along this coast, has long periods with no image. In addition, during most of the summers studied here, only one camera was working (Fig. 6). This camera covers a narrow stretch of beach facing the main entry of the coastal resort. This area is rapidly filled on sunny days, with thousands of beachgoers going further north or south along the beach to find some on the dry beach. Accordingly, the number of people from this single camera is not a good proxy for the overall beach attendance. Statistics on occupation from coastal cities or campsites is not a good beach attendance proxy, given that during bad weather conditions tourists do not go to the beach. Finally, it is important to note that beach attendance is not necessarily a good proxy for exposure as, for instance, high surf or cold water temperature can discourage beachgoers from entering the water. This research has highlighted that in order to definitely correlate SZI hazard to environmental parameters, exposure must be quantitatively known. Therefore, a major outcome of this work is that lifeguards will now count people and will systematically provide this information in the new injury report forms. 


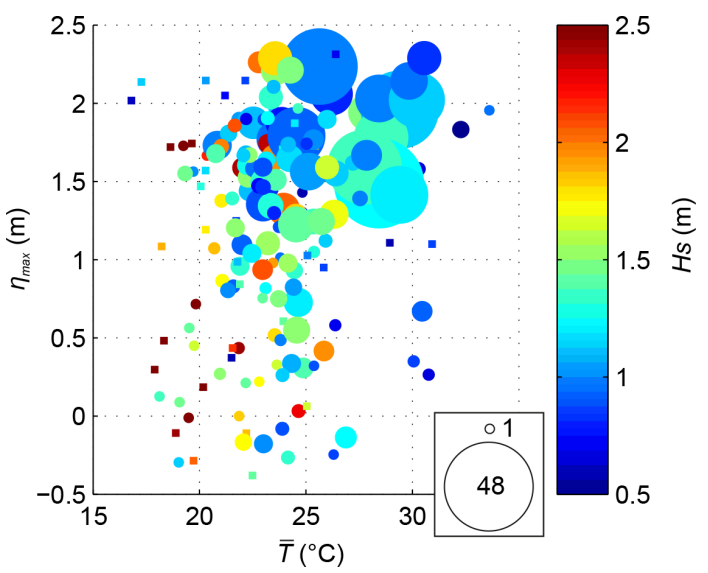

Figure 11. Daily maximum tidal elevation $\eta_{\max }$ between 15 and $19 \mathrm{~h}$ versus daily mean air temperature averaged between 11 and $19 \mathrm{~h} \bar{T}$, with significant wave height averaged between 11 and $19 \mathrm{~h}$ coloured and circle size proportional to the daily number of shorebreak-related injuries. Squares show days when there was no shorebreak-related injury.

More rip-related SZIs were found for periods with normally incident waves than for longer wave periods, which have long been known to promote the occurrence of channel rips (e.g. Castelle et al., 2006). The high occurrence of riprelated SZIs occurs during such conditions in southwestern France and are consistent with those reported along the west coasts of Devon and Cornwall in the southwest of the UK (Scott et al., 2014). However, given that breaker type and the onset of shore-break waves is not known to be affected by angle of wave incidence (Battjes, 1974), it is somewhat surprising that more shore-break-related SZIs also occur with near-shore-normal incident waves. An explanation is that more shore-normal wave incidence in summer in southwestern France is typically associated with longer-period waves (Castelle et al., 2016b). The longer-period waves result in higher wave energy flux and favour the presence of plunging and collapsing waves for a given beach slope (Battjes, 1974).

Many studies have highlighted the important tidal control on channel rip activity with maximum rip flow speed often observed at lower tide levels (e.g. Aagaard et al., 1997; Brander, 1999; Brander and Short, 2001; MacMahan et al., 2006). This is also the case on the meso-macro-tidal beaches of the southwestern coast of the UK (Austin et al., 2010; Scott et al., 2011, 2014) and southwestern France (Castelle et al., 2006; Bruneau et al., 2009, 2011), which helps explain why more rip-related SZIs in this study occur around mean low water (Fig. 5d). Of note, a disproportionate number of rip incidents took place during spring high tide levels (Fig. 5d). A detailed inspection of open-text field comments in the corresponding injury report forms indicates that approximately $25 \%$ of these drowning incidents occurred because of small-scale swash rips (Russell and McIntire, 1965; Dalrymple et al., 2011), referred to as courant de ressac by some lifeguards, which flow through the centre of beach cusps along the highest and steepest section of some beaches as wave uprush diverges at the cusp horns driving concentrated backwash streams (Masselink and Pattiaratchi, 1998). Tide also has a strong control on shore-break-related SZIs, with more injuries occurring around higher water levels (Fig. 4d). This is a logical consequence of shore-break waves being favoured by steep beach slope, with the steepest sections of the beaches of southwestern France being near spring high tide (Castelle et al., 2017).

\subsection{Impact of time of day and tidal range}

The impact of the daily TR on SZIs is more complex (Figs. 4e and 5e), although more shore-break-related SZIs overall occur for higher daily TR (Fig. 4e). This can be explained by the fact that higher tide ranges result in a longer duration of high water level and sustained hazardous shore-break waves. In addition, Fig. 12a shows that for larger daily TR, daily maximum tide elevation $\eta_{\max }$ tends to occur during the patrolled hours in the mid-to-late afternoon when beach attendance (exposure) is maximised. This can further explain why more shore-break incidents take place for a large tide range. The same applies for the disproportionate number of rip-related SZIs for higher TR (Fig. 5e), which may be the signature of spring high-tide swash rips. The other range of TR showing a disproportionate number of rip-related SZIs is around mean neap tide range (MNTR; Fig. 5e). For low TR, daily minimum tide elevation, which is when channel rip activity is maximised, tends to occur during the patrolled hours in the mid-to-late afternoon (Fig. 12b) when beach attendance (exposure) is maximised. This can explain why more rip-related SZIs occur for TR close to MNTR. In summary, (i) during larger tidal ranges, high tide occurs in the afternoon and is associated with more shore-break injuries and (ii) during smaller tidal ranges, low tide occurs in the afternoon and is associated with more rip SZIs

\subsection{Parameterised wave and tidal factors influence on SZIs}

Our results show that wave energy and tidal elevation are key environmental factors controlling both rip- and shorebreak-related SZIs. Similar observations were made by Scott et al. (2014) for rip rescues along the southwestern coast of UK, who further developed two composite parameters to determine the mode of rip behaviour and resulting hazard, namely the wave factor, $W f=H s T 02 / \overline{H s T 02}$, and the tide factor, $T f=L W-\overline{L W}$, where $\mathrm{LW}$ is the daily low water elevation and $\overline{H s T 02}$ and $\overline{L W}$ are the long-term summer averages. The average background distribution of these two composite environmental parameters are compared against their distributions associated with both ripand shore-break-related SZIs in Fig. 13. More rip-related SZIs took place on days when low water level was close to 

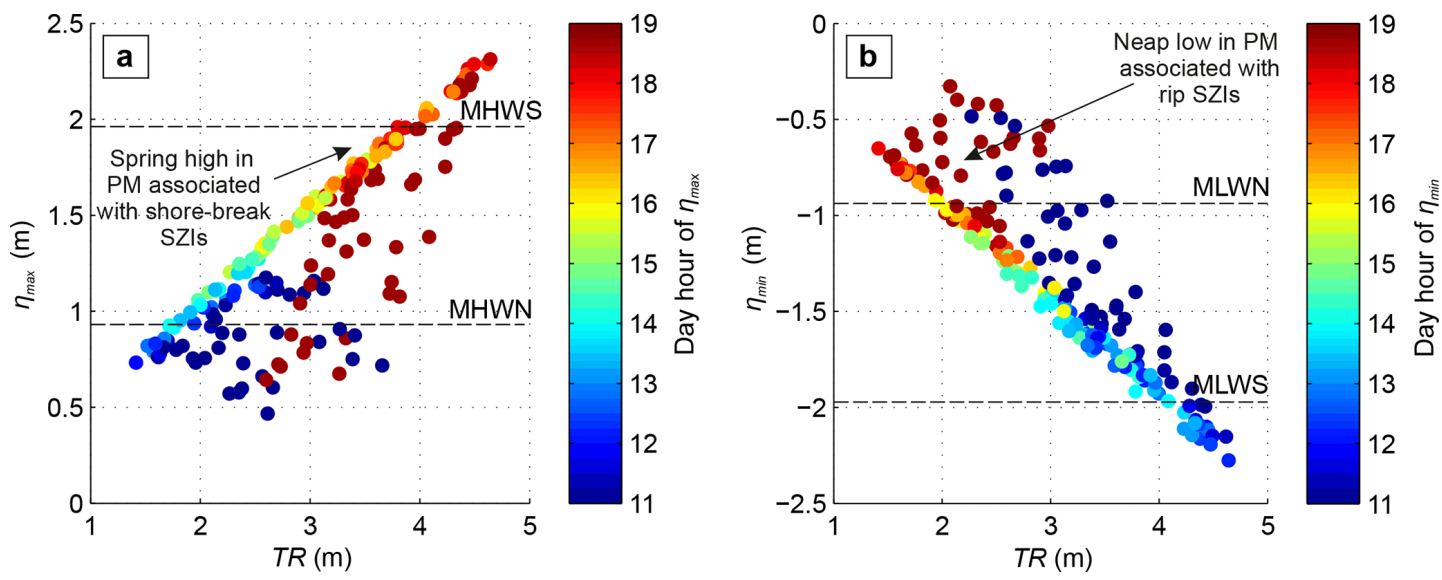

Figure 12. (a) Daily maximum tide elevation, $\eta_{\max }$, during lifeguard-patrolled hours versus daily TR with a colour bar indicating the hour of $\eta_{\max }$ occurrence; (b) daily minimum tide elevation, $\eta_{\min }$, during lifeguard-patrolled hours versus daily TR with a colour bar indicating the hour of $\eta_{\min }$ occurrence.

mean low water neap (MLWN) $(0.25 \mathrm{~m}<T f<0.5 \mathrm{~m})$. Scott et al. (2014) found a disproportionate number of rip rescues for slightly lower water levels, close to mean low water (MLW; $-0.2 \mathrm{~m}<T f<0.2 \mathrm{~m}$ ). It is important to note that here we addressed life risk related to rips using reported SZIs, while Scott et al. (2014) normalised rescues (and not necessarily drowning incidents) for beach attendance and therefore addressed rip hazard. Therefore, it is not possible to draw a sharp comparison and instead only similarities can be discussed. The slight difference in water level can be explained by evidence that rip activity, and therefore rip hazard, is maximised near mean low tide along the southwestern coast of the UK (Austin et al., 2014), while rips tend to become inactive for water levels near and below MLW in southwestern France (Castelle et al., 2006). More rip-related SZIs were also found near mean low water spring (MLWS) in southwestern France ( $T f<-0.5 \mathrm{~m}$, Fig. 13c), which may be the signature of high-tide swash rips. This was not observed in Scott et al. (2014) because the upper beaches in the southwest of the UK are gently sloping owing to finer beach sand with only little shore-break hazards. A significant peak above the background distribution was observed for $0.6<W f<1.1$, which is just below the seasonal average for the southwest of the UK (Scott et al., 2014).

In contrast, average or above seasonal average wave conditions $(W f<0.8)$ result in more rip incidents in southwestern France (Fig. 3a). A possible explanation is that Scott et al. (2014) addressed rescues in their analysis, while here only drowning incidents are analysed. The $W f$ patterns found here are, however, similar to those reported by Scott et al. (2014) for mass rescue events. Even clearer thresholds in $T f$ and Wf are observed for shore-break-related SZIs (Fig. 13b, d), but their genericity will need to be addressed at other surf beaches. $T f$ and $W f$ therefore appear as powerful composite parameters to address the primary wave and tide control

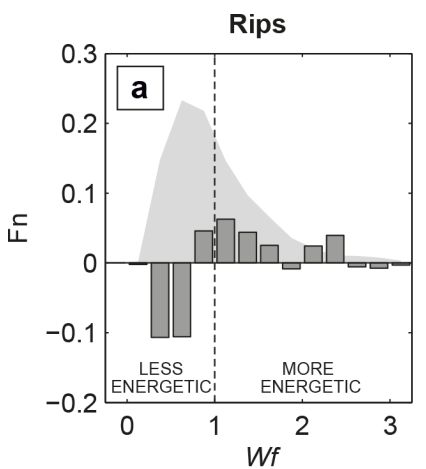

Shore-break waves
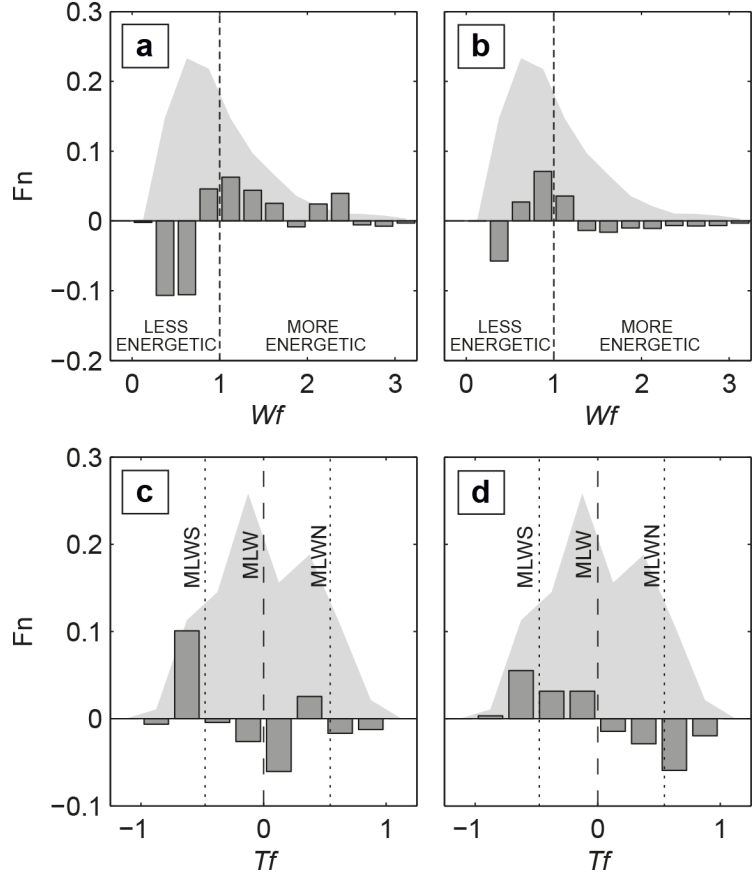

Figure 13. Normalised frequency distributions, $F n$, of $(\mathbf{a}, \mathbf{b}) W f$ $($ wave factor $=H s T 02 / \overline{H s T 02})$ and (b, d) Tf (tide factor $=L W-$ $\overline{L W}$ ) associated with (a, c) rip-related injuries and (b, d) shorebreak-related injuries. Dark grey bars are the difference between the incident-related and the "average" background frequency distributions, positive values are the proportion of the incident-related distribution greater than the background. In panels (c) and (d) the dashed lines indicate mean low water spring (MLWS), mean low water (MLW) and mean low water neap (MLWN). 

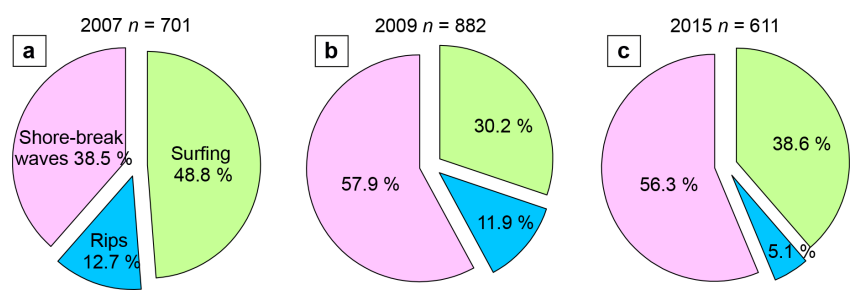

Figure 14. Percentage of SZIs by year: (a) 2007 with $\tan \beta \approx 0.06$ and deep rip channels, (b) 2009 with $\tan \beta \approx 0.16$ and deep rip channels, and (c) 2015 with $\tan \beta \approx 0.16$ and subtle rip channels.

on coast-wide life risks. It is anticipated that similar studies in other settings will provide more insight into the environmental and social parameters controlling these differences. However, this will require using consistent datasets, that is, addressing the rescues or reported SZIs and addressing life risk or hazard posed. Other composite parameters were tested for shore-break-related SZIs, but none of them provided additional insight into environmental controls. For instance, it is well established that the surf similarity parameter is indicative of breaking wave type, with large values promoting plunging and shore-break waves. Given that beach slope was not available along the entire coast and that one can assume that beach slope increases with elevation up to the berm crest, the modified surf similarity parameter $\mathrm{Bf}=\eta T 02 \sqrt{ } H s$ was tested. Not surprisingly, results (not shown) indicate that more shore-break-related injuries occur for large (>5) Bf values.

\subsection{Inter-annual morphological and climate variability controls on SZIs}

As noted in Castelle et al. (2018a), there are large data gaps in the injury report forms used here in this study, including entire lifeguard seasons, making it impossible to robustly analyse interannual variability and temporal trends of the occurrence of SZIs. The percentage of SZIs related to rips, shore-break waves and surfing activity for the three summer seasons (2007, 2009 and 2015) is given in Fig. 14, showing strong variations in the occurrence of the different types of SZIs. For example, the summer season of 2015 is characterised by a very small proportion of rip-related SZIs $(5.1 \%)$. In contrast, the 2007 summer is characterised by a low proportion of shore-break-related SZIs (38.5\%) compared to the two other summers $(57.9 \%$ and $56.3 \%)$. A preliminary analysis does not show substantial differences in overall wave climate that are able to explain this variability. However, it is well established that summer beach morphology in southwestern France shows strong interannual variability (e.g. Robinet et al., 2016; Castelle et al., 2017), which may explain such variations in SZI distribution.

To further explore this hypothesis, Fig. 15 shows beach profiles surveyed at Truc Vert beach during the three summer seasons examined in this study. It is apparent that during the
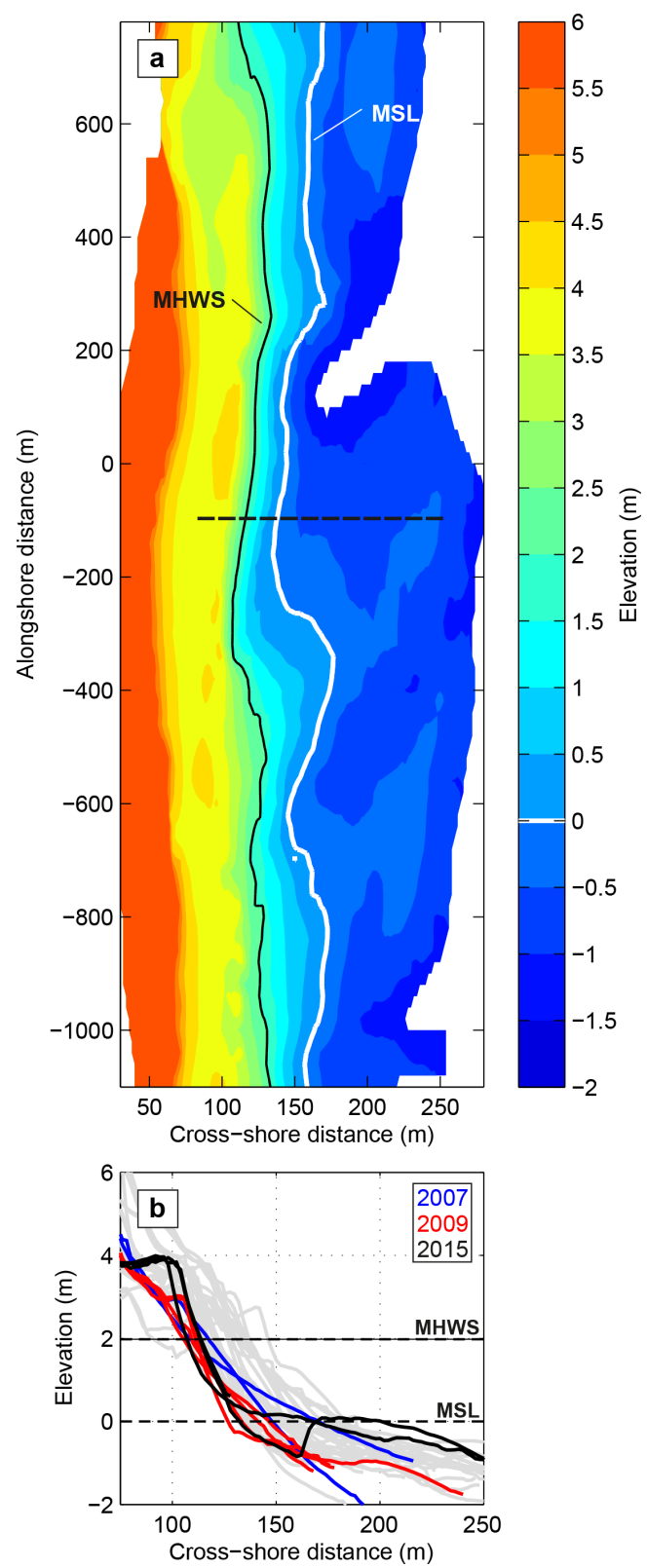

Figure 15. (a) Truc Vert beach morphology surveyed on 17 August 2015, with the colour bar indicating elevation in metres. (b) Superimposed alongshore-averaged summer (July-August) beach profiles at Truc Vert beach since 2005 in grey, with the summers of 2007, 2009 and 2015 coloured.

2007 summer (blue profiles in Fig. 15b) the upper beach was much more gently sloping $(\tan \beta \approx 0.06$ at MHWS, mean high water spring) than during the summers of 2009 and $2015(\tan \beta \approx 0.16$ at MHWS), which result in less shorebreak wave hazard and may explain the decreased number of shore-break-related SZIs (Fig. 14a). In addition, the satellite images in Fig. 16 show the presence of deep and complex rip channels incising the inner sandbar systems along the entire coast during the 2007 and 2009 summers (Fig. 16a-b), 

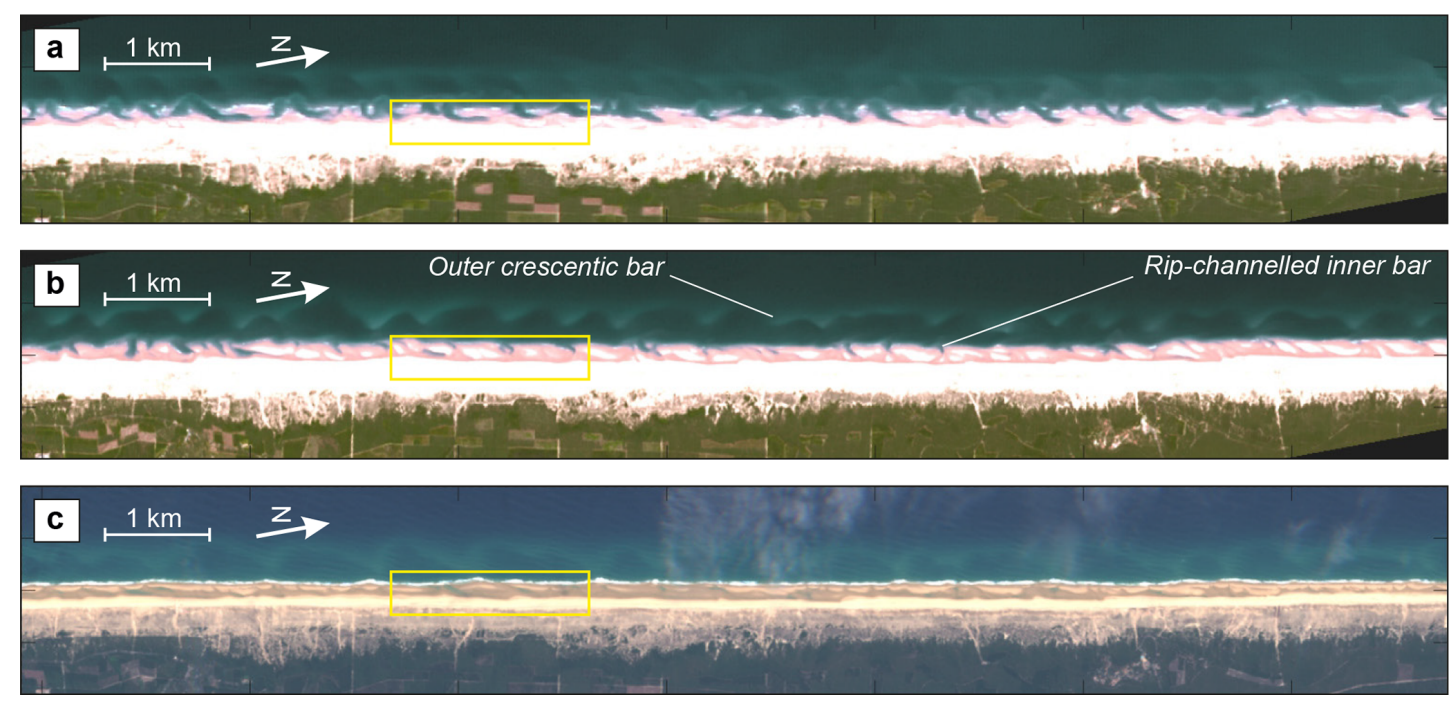

Figure 16. Satellite images of the Gironde coast around low tide near the vicinity of Truc Vert beach with the survey area in Fig. 15a indicated by the yellow box: (a) SPOT 5 image on 18 June 2007, (b) SPOT 5 image on 24 June 2009, and (c) Sentinel-2 image on 24 September 2015.

which were characterised by a large proportion of drowning incidents caused by rips. This contrasts with the reasonably alongshore-uniform sandbar during the summer of 2015 (Fig. 16c), which was not prone to rip-related incidents.

While long-term morphological data at Truc Vert (Castelle et al., 2017) and satellite images of the coast are available over the last 15 years, such a long-term SZI dataset is challenging to gather. Long-term accurate and sustainable incident reporting of beach-related injuries is a global challenge (Williamson, 2006), but it is anticipated that such a dataset, combined with long-term beach monitoring programmes, including beach survey and large-scale remote sensing, will provide new insights into the primary physical and social factors influencing interannual variability of rip- and shorebreak-related SZIs. This will also be a prerequisite to address the impact on the temporal and spatial occurrence of SZIs in new or improved public safety awareness campaigns on rips and shore-break waves in southwestern France.

An important result is that the coast-wide highest risk wave conditions for rip-related fatal and non-fatal drowning incidents is the presence of high-energy near-shore-normal incident swell waves. High-risk days with very-long-period high-energy waves, such as those that occurred on 5 August 2007 in southwestern France (Fig. 7), are consistent with the occurrence of mass rip rescue events observed in similar settings in Scott et al. (2014) in the southwestern UK. Such long-period high-energy swells can drive large infragravity waves in the surf zone (Bertin et al., 2018), with unsuspecting bathers likely to be swept into the channel at the passage of the infragravity wave crest. In such conditions, entire groups of bathers can be pulled offshore, resulting in mass rescue events (personal communication with lifeguards in southwestern France). Such very long-period near-shore-normal incident swells often occur as a result of a tropical cyclone transitioning into an extratropical cyclone in the North Atlantic (Fig. 9). An overall clockwise shift in the angle of wave incidence (more obliquely incident in southwestern France) and a decrease in wave height is expected in the wave climate of the Bay of Biscay (Charles et al., 2012). But there is also evidence for increased intensity and frequency of tropical cyclone activity in the North Atlantic during the next decades (e.g. Villarini and Vecchi, 2013). Climate change driving increased ocean temperature and an extension of warm weather conditions before and after the summer may also result in a longer tropical cyclone season and extended and higher beachgoer attendance. Collectively, this would result in increased exposure of beachgoers to hazardous very-long-period high-energy wave events in southwestern France and an increase in rips and associated SZIs.

\subsection{Synthesis and conceptual model}

Figure 17 synthesises the primary surf zone life risks occurring along the sandy beaches of southwestern France, together with the primary environmental controls. SZIs related to surfing activity can occur throughout the tide cycle when waves break away from the shore (Fig. 17b). Highenergy channel rips flow through deeper channels around low tide with the risk maximised for average or above-average wave height, near-shore-normal incident, wave conditions and spring tide range (Fig. 17c). Small-scale swash rips flowing through beach cusps located on the upper part of the beach preferably occur at spring high tide (Fig. 17e). Higher tide levels also see increased shore-break wave activity, with more incidents occurring for just below summer average, near-shore-normal incident, wave conditions and spring tide 


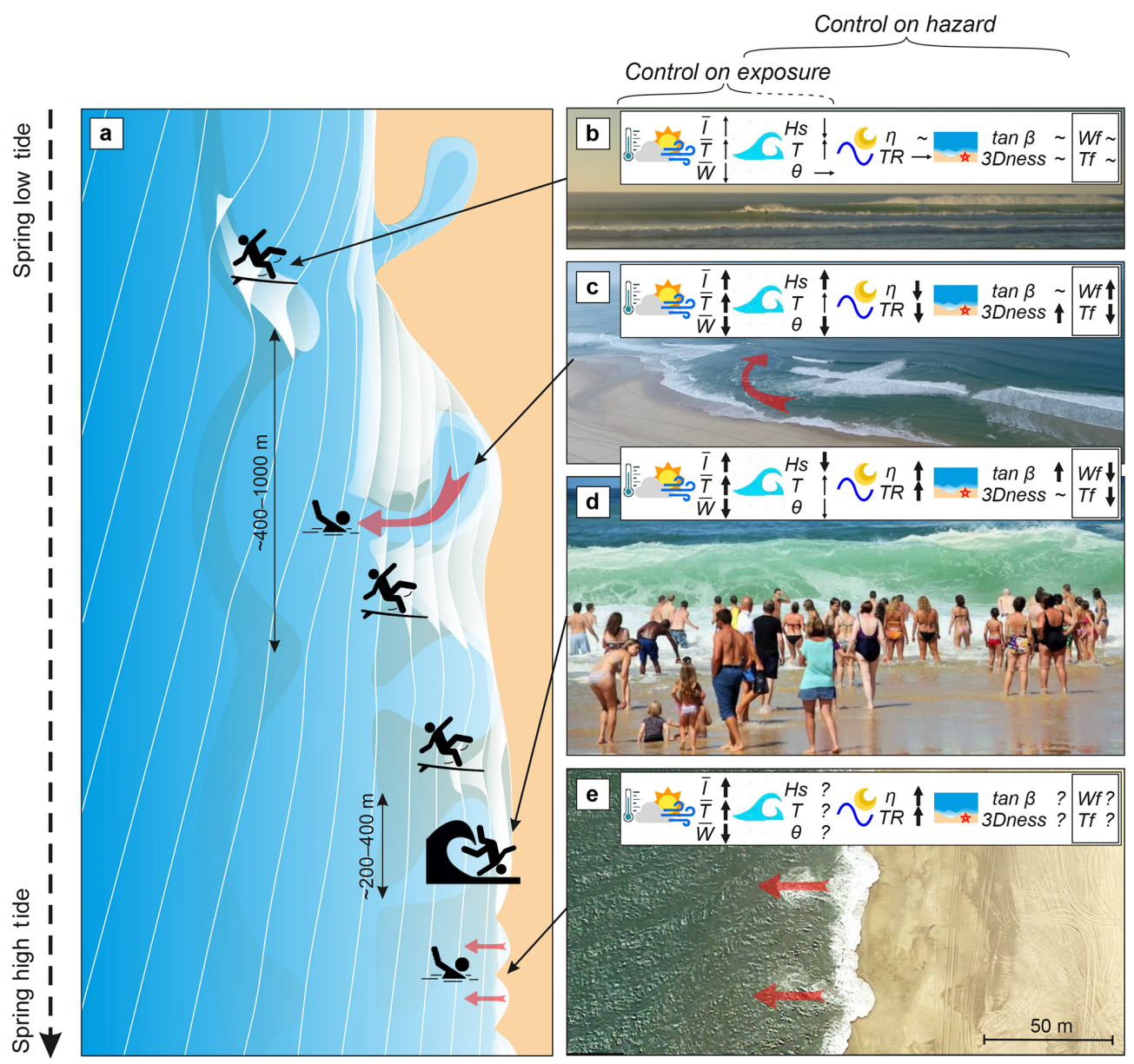

Figure 17. (a) Primary surf zone life risks along the sandy surf beaches of southwestern France with (b) high-risk surfing activity throughout the tide cycle. (c) Channel rips primarily flowing between low tide and mid-tide and maximised for near-shore-normal long-period swell. (d) Hazardous shore-break waves primarily occurring at high tide on the steepest section of the beach and (e) small-scale swash rips flowing through the centre of beach cusps at spring high tide. The primary environmental controls on beachgoer exposure and surf zone hazard are synthesised in the top boxes in panels (b)-(e), with bold arrows, “ " and "?" indicating strong, absent and unknown control, respectively. Wave and morphological controls on swash rip life risk were not addressed here as it was not possible to discriminate from channel rips.

range (Fig. 17d). Tide therefore acts as the most important and complex environmental control on rip- and shore-breakrelated SZIs along the meso-macro-tidal beaches of southwestern France. While Scott et al. (2014) identified the importance of tides in relation to rip current incidents, the complexity of the tidal control is further evident in this study along the steepest beaches of southwestern France owing to coarser sand. This results in the presence of hazardous shorebreak waves, high-tide swash rips flowing through beach cusps and surfing-related accidents, which all have different wave, tidal and morphological controls. This also suggests that lifeguard management and beachgoer safety along the coast of southwestern France would benefit from the development of different risk predictors for rip and shore-break wave hazards.

The surfing population of all abilities, including surf schools, was discriminated from regular bathers, as only a weak environmental control was found between SZIs and the surfing population (Fig. 17). This can be explained by the substantial amount of SZIs reported to occur during a surfing lesson, with training courses primarily provided in the morning and early afternoon regardless of weather and wave conditions. In addition, beginners will prefer low-energy and gentle waves, while advanced surfers will paddle out even for high-energy waves $(H s>2 \mathrm{~m})$ irrespective of weather conditions, pending low or offshore wind conditions, which greatly improve surf-break quality. Overall, more SZIs resulting from surfing activity were reported for low to moderate wave height, large wave period, west-northwest directional wave incidence and warm sunny days with low wind, independent of tidal stage or range. 


\section{Conclusions}

The large tide range and energetic, variable, and incident wave climate along surf beaches in southwestern France results in complex and highly variable surf zone injuries (SZIs) primarily caused by shore-break waves, rip currents, and surfing- and bodyboarding-related activities. Based on SZIs reported by lifeguards during the summers of 2007, 2009, and 2015, as well as tide and wave hindcasts and weather and beach morphology data, SZIs along this section of coast occurring disproportionately on warm sunny days with low wind are likely related to beachgoer exposure. Future efforts will quantify exposure and correlate this with environmental parameters.

When excluding recreational surfers from the analysis, results show that the tide exerts a strong control on both ripand shore-break-related SZIs on beaches in southwestern France. More shore-break-related SZIs occur around higher water levels and large tide ranges, as waves break across the steepest high-tide sections of the beaches. In contrast, more rip-related drownings occur at low tide, coinciding with maximum channel rip flow activity. Additional drowning incidents occur at spring high tide, presumably due to smallscale swash rips flowing through the centre of beach cusps. Above-seasonal-average wave conditions result in a disproportionate number of rip-current-related incidents in southwestern France, while more shore-break-related SZIs occur for average or below seasonal mean waves.

Overall, the higher risk wave conditions for rip-related fatal and non-fatal drowning incidents is the presence of a high-energy near-shore-normal incident swell, with low tide occurring in late afternoon coincident with maximum beach attendance. Beach and surf zone morphology is critical to the hazard posed, with summers with steep upper beach and well-developed inner-bar rip channels characterised by much more shore-break- and rip-related SZIs, respectively. These results have significant implications for the future development, or modification, of public education messaging involving interventions targeting beachgoers safety on beaches in southwestern France.

Data availability. The wave buoy data are publicly available through the French Candhis network operated by CEREMA. Weather station and tide gauge data are available from the Météo France Radome network and the SHOM, respectively. The injury data collected on beaches are not publicly available due to restriction from the French National Committee for the Protection of Data Privacy.

Author contributions. BC designed the research presented here. $\mathrm{BC}, \mathrm{TS}, \mathrm{RB}, \mathrm{JM}$, and ET designed the methodology, and $\mathrm{BC}$ executed the methodology. All authors consulted on the methodology. AR analysed the satellite images. BC prepared the manuscript, and all authors reviewed and edited the manuscript.
Competing interests. The authors declare that they have no conflict of interest.

Acknowledgements. We thank the Compagnies Républicaines de Sécurite (CRS) headquarters for providing the incident report forms as well as the lifeguard chiefs for filling the incident forms throughout the years. The surf zone injury report forms, which are still used at the time of writing this paper, were designed by JeanMichel Campagne in 1999, in close collaboration with CRS, led by Christian Mondon and civil lifeguards, fire brigade and coastal municipalities. This study includes the monitoring study site of Truc Vert labelled by the Service National d'Observation (SNO) Dynalit (https://www.dynalit.fr, last access: 25 September 2019), which surveys are financially supported by SNO Dynalit and Observatoire de la Côte Aquitaine (OCA, http://www.observatoire-cote-aquitaine. fr/, last access: 25 September 2019). We acknowledge NOAA for providing free access to the tropical cyclone data IBTrACS v3.

Financial support. This research has been supported by the Agence Nationale de la Recherche (grant no. ANR-17-CE01-0014).

Review statement. This paper was edited by Mauricio Gonzalez and reviewed by Alec Torres-Freyermuth and one anonymous referee.

\section{References}

Aagaard, T. and Vinther, N.: Cross-shore currents in the surf zone: rips or undertow?, J. Coast. Res., 24, 561-570, 2008.

Aagaard, T., Greenwood, B., and Nielsen, J.: Mean currents and sediment transport in a rip channel, Mar. Geol., 140, 25-45, 1997.

Almar, R., Castelle, B., Ruessink, B. G., Sénéchal, N., Bonneton, P., and Marieu, V.: Two- and three-dimensional double-sandbar system behaviour under intense wave forcing and a meso-macro tidal range, Cont. Shelf Res., 30, 781-792, 2010.

Angnuureng, D., Almar, R., Sénéchal, N., Castelle, B., Addo, K. A., Marieu, V., and Ranasinghe, R.: Shoreline resilience to individual storms and storm clusters on a meso-macrotidal barred beach, Geomorphology, 290, 265-276, 2017.

Ardhuin, F., Roland, A., Dumas, F., Bennis, A.-C., Sentchev, A., Forget, P., Wolf, J., Girard, F., Osuna, P., and Benoit, M.: Numerical wave modeling in conditions with strong currents: Dissipation, refraction, and relative wind, J. Phys. Oceanogr., 42, 2101-2120, 2012.

Austin, M., Scott, T., Brown, J., Brown, J. MacMahan, J., Masselink, G., and Russell, P.: Temporal observations of rip current circulation on a macro-tidal beach, Cont. Shelf Res., 30, 1149$1165,2010$.

Austin, M. J., Scott, T. M., Russell, P. E., and Masselink, G.: Rip current prediction: development, validation, and evaluation of an operational tool, J. Coast. Res., 29, 283-300, 2013.

Austin, M. J., Masselink, G., Scott, T. M., and Russell, P. E.: Water level controls on macro-tidal rip currents, Cont. Shelf Res., 75, 28-40, 2014. 
Balouin, Y., Rey-Valette, H., and Picand, P.-A.: Automatic assessment and analysis of beach attendance using video images at the lido of Sète Beach, France, Ocean Coast. Manage., 102, 114122, 2014.

Battjes, J. A.: Surf similarity, in: Proc. 14th International Conference on Coastal Engineering, Copenhagen, Denmark, 466-480, 1974.

Beratan, K. K. and Osborne, R. H.: Frequency and demographic aspects in shallow-water diving accidents in southern California, in: Shallow-water diving accidents at southern California ocean beaches: demographic, sedimentologic, medical, legal and management perspectivesm edited by: Osborne, R. H., University of Southern California, Los Angeles, CA, USA, 1987.

Bertin, X., de Bakker, A., van Dongeren, A., Coco, G., Andre, G., Ardhuin, F., Bonneton, P., Bouchette, F., Castelle, B., Crawford, W. C., Davidson, M., Deen, M., Dodet, G., Guerin, T., Inc, K., Leckler, F., Mcall, R., Muller, H., Olabarrieta, M., Roelvink, J. A., Ruessink, B.G., Sous, D., Stutzmann, E., and Tissier, M.: Infragravity waves: from driving mechanisms to impacts, EarthSci. Rev., 177, 774-799, 2018.

Boudière, E., Maisondieu, C., Ardhuin, F., Accensi, M., PineauGuillou, L., and Lepesqueur, J.: A suitable metocean hindcast database for the design of marine energy converters, Int. J. Mar. Energ., 3-4, 40-52, 2013.

Bradstreet, A., Brander, R., McCarroll, J., Brighton, B., DomineyHowes, D., Drozdzewski, D., Sherker, S., Turner, I., Roberts, A., and MacMahan, J.: Rip current survival principles: towards consistency, J. Coast. Res., 72, 85-92, 2014.

Brander, R. W.: Field observations on the morphodynamic evolution of a low-energy rip current system, Mar. Geol., 157, 199-217, 1999.

Brander, R. W. and Scott, T.: Science of the Rip Current Hazard, in: The Science of Beach Lifeguarding: Principles and Practice, edited by: Tipton, M., Wooler, A., and Reilly, T., CRC Press, Boca Raton, 67-86, 2016.

Brander, R. W. and Short, A. D.: Flow kinematics of low-energy rip current systems, J. Coast. Res., 17, 468-481, 2001.

Brander, R. W., Bradstreet, A., Sherker, S., and MacMahan, J.: Responses of swimmers caught in rip currents: perspectives on mitigating the global rip current hazard, International Journal of Aquatic Research and Education, 5, 476-482, 2011.

Brighton, B., Sherker, S., Brander, R., Thompson, M., and Bradstreet, A.: Rip current related drowning deaths and rescues in Australia 2004-2011, Nat. Hazards Earth Syst. Sci., 13, 10691075, https://doi.org/10.5194/nhess-13-1069-2013, 2013.

Brumaud, S.: Saison touristique 2015 en Aquitaine - La fréquentation des hôtels et campings au beau fixe, INSEE Analyses Nouvelle-Aquitaine, available at: https://www.insee.fr/fr/ statistiques/1908387 (last access: 25 September 2019), 2016 (in French).

Bruneau, N., Castelle, B., Bonneton, P., Pedreros, R., Almar, R., Bonneton, N., Bretel, P., Parisot, J.-P., and Senechal, N.: Field observations of an evolving rip current on a meso-macrotidal well-developed inner bar and rip morphology, Cont. Shelf Res., 29, 1650-1662, 2009.

Bruneau, N., Bonneton, P., Castelle, B., and Pedreros, R.: Modeling rip current circulations and vorticity in a high-energy meso-environment, J. Geophys. Res.-Oceans, 116, C07026, https://doi.org/10.1029/2010JC006343, 2011.
Butel, R., Dupuis, H., and Bonneton, P.: Spatial variability of wave conditions on the French Atlantic coast using in situ data, J. Coast. Res. Special Issue, 36, 96-108, 2002.

Castelle, B., Bonneton, P., Senechal, N., Dupuis, H., Butel, R., and Michel, D.: Dynamics of wave-induced currents over an alongshore non-uniform multiple-barred sandy beach on the Aquitanian Coast, France, Cont. Shelf Res., 26, 113-131, 2006.

Castelle, B., Bonneton, P., Dupuis, H., and Sénéchal, N.: Double bar beach dynamics on the high-energy meso-macrotidal French Aquitanian Coast: a review, Mar. Geol., 245, 141-159, 2007.

Castelle, B., Scott, T., Brander, R. W., and McCarroll, R. J.: Rip current types, circulation and hazard, Earth-Sci. Rev., 163, 1-21, 2016a.

Castelle, B., McCarroll, R. J., Brander, R. W., Scott, T., and Dubarbier, B.: Modelling the alongshore variability of optimum rip current escape strategies on a multiple rip-channelled beach, Nat. Hazards, 81, 664-686, 2016b.

Castelle, B., Bujan, S., Ferreira, S., and Dodet, G.: Foredune morphological changes and beach recovery from the extreme 2013/2014 winter at a high-energy sandy coast, Mar. Geol., 385 , 41-55, 2017.

Castelle, B., Brander, R. W., Tellier, E., Simonnet, B., Scott, T., McCarroll, R. J., Campagne, J. M., Cavailhes, T., and Lechevrel, P.: Surf zone hazards and injuries on beaches in SW France, Nat. Hazards, 93, 1317-1335, 2018a.

Castelle, B., Guillot, B., Marieu, V., Chaumillon, E., Hanquiez, V., Bujan, S., and Poppeschi, C.: Spatial and temporal patterns of shoreline change of a $280-\mathrm{km}$ high-energy disrupted sandy coast from 1950 to 2014: SW France, Estuar. Coast. Shelf S., 200, 212 223, 2018b.

Chang, S. K., Tominaga, G. T., Wong, J. H., Weldon, E. J., Kaan, K. T., and Kenneth, T.: Risk factors for water sports-related cervical spine injuries, J. Trauma, 60, 1041-1046, 2006.

Charles, E., Idier, D., Delecluse, P., Déqué, M., and Le Cozannet, G.: Climate change impact on waves in the Bay of Biscay, France, Ocean Dynam., 62, 831-848, 2012.

Dalrymple, R. A., MacMahan, J. H., Reniers, A. J. H. M., and Nelko, V.: Rip currents, Annu. Rev. Fluid Mech., 43, 551-581, 2011.

Davidson, M. A., Turner, I. L., Splinter, K. D., and Harley, M. D.: Annual prediction of shoreline erosion and subsequent recovery, Coast. Eng., 130, 14-25, 2017.

Diehm, R. and Armatas, C.: Surfing: An avenue for socially acceptable risk-taking, satisfying needs for sensation seeking and experience seeking, Pers. Indiv. Differ., 36, 663-677, 2004.

Dimmick, S., Brazier, D., Wilson, P., and Anderson, S. E.: Injuries of the spine sustained whilst surfboard riding, Emerg. Radiol., 20, 25-31, 2013.

Dodet, G., Castelle, B., Masselink, G., Scott, T., Davidson, M., Floc'h, F., Jackson, D., and Suanez, S.: Beach recovery from extreme storm activity during the 2013-14 winter along the Atalantic coast of Europe, Earth Surf. Proc. Land., 44, 393-401, https://doi.org/10.1002/esp.4500, 2019.

Drozdzewski, D., Shaw, W., Dominey-Howes, D., Brander, R., Walton, T., Gero, A., Sherker, S., Goff, J., and Edwick, B.: Surveying rip current survivors: preliminary insights into the experiences of being caught in rip currents, Nat. Hazards Earth Syst. Sci., 12, 1201-1211, https://doi.org/10.5194/nhess-12-1201-2012, 2012. 
Drozdzewski, D., Roberts, A., Dominey-Howes, D., and Brander, $\mathrm{R}$ : The experiences of weak and non-swimmers caught in rip currents at Australian beaches, Aust. Geogr., 46, 15-32, 2015.

Dupoux, J. E., Bernard-Catinat, G., and Brunel, J. M.: Réactualisation du traitement d'urgence de la noyade, Bordeaux Méd, 14, 1095-1100, 1981 (in French).

Dusek, G. and Seim, H.: A probabilistic rip current forecast model, J. Coast. Res., 29, 909-925, 2013.

Gilchrist, J. and Branche, C.: Lifeguard Effectiveness, in: The Science of Beach Lifeguarding, edited by: Tipton, M. and Wooler, A., CRC Press, Boca Raton, USA, 2016.

Guillen, J., Garcia-Olivares, A., Ojeda, E., Osorio, A., Chic, O., and Gonzalez, R.: Long-term quantification of beach users using video monitoring, J. Coast. Res., 24, 1612-1619, 2008.

Houser, C., Arnott, R., Ulzhofer, S., and Barrett, G.: Nearshore circulation over transverse bar and rip morphology with oblique wave forcing, Earth Surf. Proc. Land., 38, 1269-1279, 2013.

Ibarra, E. M.: The use of webcam images to determine touristclimate aptitude: favourable weather types for sun and beach tourism on the Alicante coast (Spain), Int. J. Biometeorol., 55, 373-385, https://doi.org/10.1007/s00484-010-0347-8, 2011.

Kennedy, D. M., Sherker, S., Brighton, B., Weir, A., and Woodroffe, C. D.: Rocky coast hazards and public safety: moving beyond the beach in coastal risk management, Ocean Coast. Manage., 82, 85-94, 2013.

Lafon, V., Dupuis, H., Butel, R., Castelle, B., Michel, D., Howa, H., and De Melo Apoluceno, D.: Morphodynamics of nearshore rhythmic sandbars in a mixed energy environment (SW France): II. Physical forcing analysis, Estuar. Coast. Shelf S., 65, 449462, 2005.

Lascody, R. L.: East central Florida rip current program, Natl. Weather Dig., 22, 25-30, 1998.

Le Cann, B.: Barotropic tidal dynamics of the Bay of Biscay shelf: observations, numerical modelling and physical interpretation, Cont. Shelf Res., 10, 723-758, 1990.

Lorin, J. and Viguier, J.: Hydrosedimentary conditions and present evolution of Aquitaine Coast, Bull. Inst. Géol. Bassin Aquitaine, 41, 95-108, 1987.

Lowdon, B. J., Pateman, N. A., and Pitman, A. J.: Surfboard-riding injuries, Med. J. Aust., 2, 613-616, 1983.

Lushine, J. B.: A study of rip current drowning and related weather factors, Natl. Weather Dig., 16, 15-31, 1991.

MacMahan, J. H., Thornton, E. B., Stanton, T. P., and Reniers, A. J. H. M.: RIPEX: observations of a rip current system, Mar. Geol., 218, 118-134, 2005.

MacMahan, J. H., Thornton E. B., and Reniers, A. J.: Rip current review, Coast. Eng., 53, 191-208, 2006.

Masselink, G. an Pattiaratchi, C. B.: Morphological evolution of beach cusps and associated swash circulation patterns, Mar. Geol., 146, 93-113, 1998.

McCarroll, R. J., Brander, R. W., MacMahan, J. H., Turner, I. L., Reniers, A. J. H. M., Brown, J. A., Bradstreet, A., and Sherker, S.: Evaluation of swimmer-based rip current escape strategies, Nat. Hazards, 71, 1821-1846, 2014.

McCarroll, R. J., Castelle, B., Brander, R. W., and Scott, T.: Modelling rip current flow and bather escape strategies across a transverse bar and rip channel morphology, Geomorphology, 246, 502-518, 2015.
McCarroll, R. J., Brander, R. W., Scott, T., and Castelle, B.: Bathymetric controls on rotational surfzone currents, J. Geophys. Res.Earth, 123, 1295-1316, https://doi.org/10.1029/2017JF004491, 2018.

Menezes, R. A. and Costa, R. V. C.: Resgate e recuperação de 12.037 afogados, J. Bras. Med., 9, 50-64, 1972.

Moran, K. and Weber, J.: Surfing injuries requiring first aid in New Zealand, 2007-2012, Int. J. Aquat. Res. Educ., 7, 192-203, 2013.

Moulton, M., Elgar, S., Raubenheimer, B., Warner, J. C., and Kumar, N.: Rip currents and alongshore flows in single channels dredged in the surf zone, J. Geophys. Res.-Oceans, 122, 37993816, https://doi.org/10.1002/2016JC012222, 2017a.

Moulton, M., Dusek, G., Elgar, S., and Raubenheimer, B.: Comparison of Rip Current Hazard Likelihood Forecasts with Observed Rip Current Speeds, Weather Forecast., 32, 1659-1666, $2017 \mathrm{~b}$.

Muller, M. W.: Beach replenishment and surf-zone injuries along the coast of Delmarva, USA, Ocean Coast. Manage., 151, 127133, 2018.

Nathanson, A. T.: Surfing Injuries, in: Adventure and Extreme Sports Injuries, edited by: Mei-Dan, O. and Carmont, M., Springer, London, UK, 2013.

NOAA: National Weather Service Weather Fatality, Injury and Damage Statistics, available at: https://www.weather.gov/ hazstat/ (last access: 25 September 2019), 2017.

Pianca, C., Holman, R., and Siegle, E.: Shoreline variability from days to decades: Results of long-term video imaging, J. Geophys. Res.-Oceans, 120, 2159-2178, https://doi.org/10.1002/2014JC010329, 2015.

Puleo, J. A., Hutschenreuter, K., Cowan, P., Carey, W., ArfordGranholm, M., and McKenna, K. K.: Delaware surf zone injuries and associated environmental conditions, Nat. Hazards, 81, 845867, 2016.

RNLI: RNLI 2017 Operational Statistics, 13 pp., available at: http: //rnli.org (last access: 25 September 2019), 2017.

Robinet, A., Castelle, B., Idier, D., Le Cozannet, G., Déqué, M., and Charles, E.: Statistical modeling of interannual shoreline change driven by North Atlantic climate variability spanning 2000-2014 in the Bay of Biscay, Geo-Mar. Lett., 36, 479-490. https://doi.org/10.1007/s00367-016-0460-8, 2016.

Robles, L. A.: Cervical spine injuries in ocean bathers: wave-related accidents, Neurosurgery, 58, 920-923, 2006.

Roelvink, J. A., Reniers, A. J. H. M., van Dongeren, A., de Vries, J. V., McCall, R., and Lescinski, J.: Modelling storm impacts on beaches, dunes and barrier islands, Coast. Eng., 56, 1133-1152, 2009.

Russell, R. J. and McIntire, W. G.: Beach cusps, Geol. Soc. Am. Bull., 76, 307-320, 1965.

Scott, T. M., Russell, P. E., Masselink, G., Austin, M. J., Wills, S., and Wooler, A.: Rip current hazards on large-tidal beaches in the United Kingdom, in: Rip Currents: Beach Safety, Physical Oceanography and Wave Modeling, edited by: Leatherman, S. and Fletemeyer, J., CRC Press, Boca Raton, 225-242, 2011.

Scott, T. M., Masselink, G., Austin, M. J., and Russell, P.: Controls on macrotidal rip current circulation and hazard, Geomorphology, 214, 198-215, 2014.

Splinter, K. D., Turner, I. L., Davidson, M. A., Barnard, P., Castelle, B., and Oltman-Shay, J.: A generalized equilibrium model for predicting daily to interannual shoreline response, J. Geophys. 
Res., 119, 1936-1958, https://doi.org/10.1002/2014JF003106, 2014.

Splinter, K. D., Gonzalez, M. V. G., Oltman-Shay, J., Rutten, J., and Holman, R.: Observations and modelling of shoreline and multiple sandbar behaviour on a high-energy meso-tidal beach, Cont. Shelf Res., 159, 33-45, 2018.

Stokes, C., Masselink, G., Revie, M., Scott, T., Purves, D., and Walters, T.: Application of multiple linear regression and Bayesian belief network approaches to model life risk to beach users in the UK, Ocean Coast. Manage., 139, 12-23, 2017.

Tastet, J.-P. and Pontee, N. P.: Morpho-chronology of coastal dunes in Médoc: e new interpretation of Holocene dunes in Southwestern France, Geomorphology, 25, 93-109, 1998.

Tolman, H. L.: User manual and system documentation of WAVE WATCH III version 4.18, NOAA/NWS/NCEP/MMAB Technical Note 316, NOAA/NWS/NCEP/MMAB 194, 282 pp., 2014.

USLA: 2010-2014 National Lifesaving Statistics, available at: http://arc.usla.org/Statistics/current.asp?Statistics=5 (last access: 25 September 2019), 2015.
Villarini, G. and Vecchi, G. A.: Projected Increases in North Atlantic Tropical Cyclone Intensity from CMIP5 Models, J. Climate, 26, 3231-3240, https://doi.org/10.1175/JCLI-D-12$00441.1,2013$.

West, N.: Beach Use and Behaviors, in: Encyclopedia of Coastal Science. Encyclopedia of Earth Science Series, edited by: Schwartz, M. L., Springer, Dordrecht, the Netherlands, 2005.

Winter, G., van Dongeren, A. R., de Schipper, M. A., an van Thiel de Vries, J. S. M.: Rip currents under obliquely incident wind waves and tidal longshore currents, Coast. Eng., 89, 106-119, 2014.

Williamson, A.: Feasibility study of a water safety data collection for beaches, J. Sci. Med. Sport., 9, 243-248, 2006.

Wright, L. D. and Short, A. D.: Morphodynamic variability of surf zones and beaches: a synthesis, Mar. Geol., 56, 93-118, 1984. 